Talanta, Volume 233, 1 October 2021, 122611, https://doi.org/10.1016/j.talanta.2021.122611

\title{
Simplified miniaturized analytical set-up based on molecularly imprinted polymer directly coupled to UV detection for the determination of benzoylecgonine in urine
}

\author{
Thomas Bouvarel ${ }^{\mathrm{a}}$, Christophe Chendo ${ }^{\mathrm{a}}$, Nathalie Delaunay ${ }^{\mathrm{a}}$, Valérie Pichon ${ }^{\mathrm{a}, \mathrm{b} *}$ \\ ${ }^{a}$ Department of Analytical, Bioanalytical Sciences and Miniaturization (LSABM) - Chemistry, Biology \\ and Innovation (CBI), ESPCI Paris, CNRS, PSL University, 75005 Paris, France

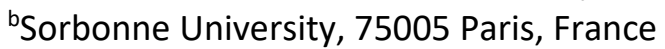 \\ *: Corresponding author: valerie.pichon@espci.fr (Pr. V. Pichon), Tel: +33 140794 772, \\ Fax: +33 140794 776. LSABM, ESPCI Paris, 10 rue Vauquelin, 75005 Paris, France
}

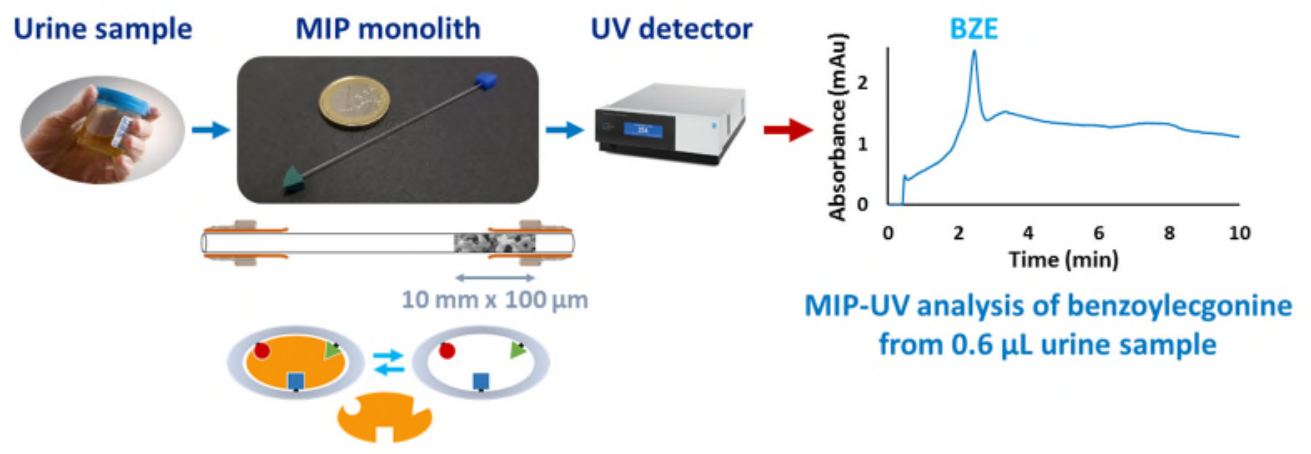

\begin{abstract}
A simple, selective, and sensitive method involving a miniaturized solid phase extraction step based on a monolithic molecularly imprinted polymer (MIP) directly coupled on-line to UV detection was developed for the determination of benzoylecgonine (BZE) in complex biological samples. Monolithic MIPs were prepared into $100 \mu \mathrm{m}$ internal diameter fused-silica capillaries either by thermal or photopolymerization. While leading to similar selectivities with respect to BZE, photopolymerization has made it possible to produce monoliths of different lengths that can be adapted to the targeted miniaturized application. The homogeneous morphology of these monolithic MIPs was evaluated by scanning electron microscopy prior to measuring their permeability. Their selectivity was evaluated leading to imprinting factors of $2.7 \pm 0.1$ for BZE and $4.0 \pm 0.6$ for cocaine (selected as template for the MIP synthesis) with polymers resulting from three independent syntheses, showing both the high selectivity of the MIPs and the reproducibility of their synthesis. After selecting the appropriate capillary length and the set-up configuration and optimizing the extraction protocol to promote selectivity, the extraction of BZE present in human urine samples spiked at 150,250 , and $500 \mathrm{ng} \mathrm{mL}^{-1}$ was successfully carried out on the monolithic MIP and coupled directly on-line with UV detection. The very clean-baseline of the resulting chromatograms revealing only the peak of interest for BZE illustrated the high selectivity brought by the monolithic MIP. Limits of detection and quantification of $56.4 \mathrm{ng} \mathrm{mL}^{-1}$ and $188.0 \mathrm{ng} \mathrm{mL}^{-1}$ were achieved in urine samples, respectively. It is therefore possible to achieve analytical threshold in accordance with the legislation on BZE detection in urine without the need for an additional chromatographic separation.
\end{abstract}


Keywords: Benzoylecgonine; Miniaturization; Molecularly Imprinted Polymer; Monolith; Urine

\begin{abstract}
Abbreviations
$\mathrm{ACN}$, Acetonitrile; AIBN, Azo-N,N'-diisobutyronitrile; BZE, Benzoylecgonine; CL, Cross-linking agent; COC, Cocaine; i.d., Internal diameter; IF, Imprinting factor; LOD, Limit of detection; LOQ, Limit of quantification; MAA, Methacrylic acid; Y-MAPS, 3-(trimethoxysilyl)propyl methacrylate; MIP, Molecularly imprinted polymer; nanoLC, Nano-liquid chromatography; NIP, Non-imprinted polymer; o.d., Outer diameter; P, Porogen; RSD, Relative standard deviation; SEM, Scanning electron microscopy; SPE, Solid phase extraction; T, Template; TRIM, Trimethylolpropane trimethacrylate.
\end{abstract}

\title{
1-Introduction
}

Miniaturization has become a major issue in analytical chemistry whatever the field of application, whether clinical, environmental, food, toxicological, etc. and whatever the nature of the target compounds. The potential benefits of miniaturization are enormous, based on the principle that smallscale processes consume less time, samples, and reagents [1]. However, in some cases, miniaturization can have detrimental effects on separation, because the reduction of the separation lengths can lead to a loss of separation power, which is crucial for overcoming sample complexity, especially when target analytes are present at trace levels. In this context, the introduction of a selective concentration and purification step into miniaturized devices seems very interesting.

Solid phase extraction (SPE) is routinely used for the extraction of compounds from liquid samples or solid matrix extracts $[2,3]$. Many works have demonstrated the feasibility of miniaturizing this technique by the possibility of synthesizing in situ organic monoliths into a capillary or a chip channel [4-9]. However, the extraction on a polymeric sorbent results from non-selective interactions that depend on the polarity of the molecules, which lead to the co-extraction of compounds with similar polarities to the targets. To overcome this lack of selectivity, various extraction supports leading to a molecular recognition mechanism have been developed such as molecular imprinted polymers (MIPs). These sorbents are synthetic polymers possessing specific cavities with a steric and functional complementarity to that of the template molecule used for their synthesis. They offer many advantages including chemical and thermal stability but also easy, cheap, and rapid preparation for a wide variety of applications such as drug delivery [10-12], sensors [13-16], biomimetic catalyst in organic synthesis [17], separation of structural analogs and enantiomers [18], or extraction [19].

MIPs can also be integrated into miniaturized devices, especially when the template, which is essential for MIP synthesis, is expensive or difficult to synthesize [20]. Several authors succeeded in introducing imprinted phases for exhaustive and miniaturized SPE by the synthesis of thin films [21,22], by packing MIP particles in specially designed chips $[23,24]$, or by grafting MIP on the surface of a core monolith [25-27]. Another approach is to synthesized a porous monolithic imprinted polymer directly into capillaries and chip microchannels [20]. Indeed, monoliths are a way of overcoming the constraints related to the use of particles (immobilization, homogeneous packing...) or thin films (low amount of phase).

Miniaturized monolithic MIPs were first reported for chiral separations in capillary electrochromatography by Schweitz et al. $[28,29]$ before being applied to extraction purposes. Recently, monolithic MIPs were developed and used off-line before conventional analysis as extraction sorbents in various more or less miniaturized formats, such as pipet-tips [30,31], hollow-fiber membranes [32], or capillaries with internal diameter (i.d.) of $500 \mu \mathrm{m}$ [33-35]. Monolithic MIPs prepared in capillaries of 250-530 $\mu \mathrm{m}$ i.d. were also coupled on-line with separation columns, but having conventional 2.1 [36] or $4.6 \mathrm{~mm}$ i.d. [37-39], thus only partially miniaturizing the analytical method. Besides, to our knowledge, only two works are related to the on-line coupling of a capillary containing a MIP (100 $\mu \mathrm{m}$ i.d.) with a miniature separation column of 180 [25] or $75 \mu \mathrm{m}$ i.d. [40]. One 
of them described the synthesis of a MIP grafted on the surface of a poly(trimethylolpropane trimethacrylate) core monolith [25]. The second one, reported by our group, is related to the direct in situ synthesis of a monolithic MIP filling the entire section of the capillary [40].

In this last case, the monolithic MIP (50 mm x $100 \mu \mathrm{m}$ i.d.) was coupled on-line with a $75-\mu \mathrm{m}$ i.d. column for the determination of cocaine in plasma and saliva samples by SPE, nano-liquid chromatography (nanoLC), and UV detection [40]. The MIP was obtained with methacrylic acid (MAA) as monomer, trimethylolpropane trimethacrylate (TRIM) as cross-linker, acetonitrile (ACN) containing $10 \%$ isooctane as porogen, and thermal initiation at $60^{\circ} \mathrm{C}$.

In a constant effort to miniaturize and simplify the analytical device, the aim of this work was to make the most of the selectivity brought by the monolithic MIP to remove the separation column and online couple the monolithic MIP directly with UV detection for the analysis of a target compound in biological fluids. As the previous study mainly showed the potential of this MIP for the selective extraction of cocaine [40], this study focused on the possibility to develop a system adapted to the survey of cocaine consumers by developing an analytical device allowing the detection of BZE, the main urinary metabolite of cocaine. Indeed, this drug is excreted in urine as BZE up to $52 \%$, while less than $1 \%$ of cocaine is excreted as unaltered form [41]. Although developed for cocaine, the possibility of selectively retaining BZE with this MIP was demonstrated by retention measures in a pure medium. First, a cocaine imprinted poly(MAA-co-TRIM) monolith synthesized as previously described by thermal initiation [40] was employed to investigate the feasibility of such a simple device applied to a pure medium. In order to reduce the length of the monolith, thermal initiation was replaced by UV irradiation. The resulting monoliths were compared to the previous one in terms of permeability and selectivity. Then, a $10 \mathrm{~mm}$ length monolithic MIP was directly connected on-line to UV detection and applied to the analysis of BZE present in urine samples.

\section{2- Materials and methods}

\section{2-2 Chemicals and reagents}

Stock solutions at $1 \mathrm{mg} \mathrm{mL}^{-1}$ of BZE in $\mathrm{MeOH}$ and cocaine base were provided by Sigma-Aldrich (SaintQuentin-Fallavier, France). The working solutions at $1 \mu \mathrm{g} \mathrm{mL}^{-1}$ were obtained by dilution of the stock solution (1 $\mathrm{mg} \mathrm{mL}^{-1}$ ) in HPLC-grade ACN (Carlo Erba, Val-de-Reuil, France). These solutions were stored at $-20^{\circ} \mathrm{C}$. MeOH, EtOH, and isooctane were purchased from Carlo Erba. Acetic acid and anhydrous ACN were provided by Sigma-Aldrich. $1 \mathrm{M} \mathrm{NaOH}$ and $0.1 \mathrm{M} \mathrm{HCl}$ were obtained using deionized water (MilliQ purification system, Millipore, Molsheim, France) and Titrisol solutions from Merck (Darmstadt, Germany).

MAA, TRIM, and 3-(trimethoxysilyl)propyl methacrylate ( $\gamma$-MAPS) were purchased from Sigma-Aldrich. Azo- $N, N^{\prime}$-diisobutyronitrile (AIBN) was purchased from Acros Organics (Noisy-le-Grand, France). MAA was distilled under vacuum in order to remove inhibitors and stored at $-20^{\circ} \mathrm{C}$. TRIM, AIBN, and $\gamma$-MAPS were of satisfactory purity so they were used without further purification. Fused-silica capillaries with a UV transparent fluorocarbon polymer coating (PTFE-coated silica capillaries, $100 \mu \mathrm{m}$ i.d. x $375 \mu \mathrm{m}$ outer diameter (o.d.)) were purchased from Polymicro Technologies (Photon Lines, Saint Germain-enLaye, France).

\section{2-3 In situ preparation of the monolithic polymers}

The monolithic polymers were prepared in situ in fused silica capillaries by a two-step method adapted from the procedure described in a previous work [40]. Prior to polymerization, the inner wall of the capillaries was activated with $\psi$-MAPS to anchor the monolith. Briefly, the capillaries were first rinsed with water, then activated by flushing $1 \mathrm{M} \mathrm{NaOH}$ for $30 \mathrm{~min}$. After a washing step with water, $0.1 \mathrm{M}$ $\mathrm{HCl}$ was flushed for $30 \mathrm{~min}$. The silanization was then achieved with $250 \mu \mathrm{L}$ of $\psi$-MAPS in $1 \mathrm{~mL}$ of EtOH, 
with a $\mathrm{pH}$ adjusted to 3.5 by acetic acid, for at least $1 \mathrm{~h}$ at room temperature. The capillaries were washed with $\mathrm{EtOH}$ and finally dried with nitrogen.

The template molecule ( $T$, cocaine), functional monomer ( $M, M A A)$, cross-linking agent ( $C L, T R I M)$, and radical initiator (AIBN) were dissolved in porogen ( $\mathrm{P}, \mathrm{ACN}$ containing $10 \%$ isooctane) with a molar ratio $\mathrm{T} / \mathrm{M} / \mathrm{CL}$ of $1 / 4 / 20$. Then the polymerization mixture was purged with nitrogen for $5 \mathrm{~min}$ to get rid of oxygen and introduced in $150 \mathrm{~mm}$-long capillaries. After sealing both ends of the capillaries with rubber septa, two initiation modes were performed. For thermal initiation, the capillaries were immersed in a thermostated water bath at $60^{\circ} \mathrm{C}$ and the polymerization was allowed to proceed during $24 \mathrm{~h}$. For UV irradiation, the capillaries were protected with a mask so that the imprinted monolith was located only in the part of 10,25 , or $50 \mathrm{~mm}$ exposed to UV light. They were then placed into a Spectrolinker XL-1500 UV crosslinker from Spectronics Corporation (Westbury, NY, USA), equipped with 6 UV lamps $(6 \times 155 \mathrm{~W}, 365 \mathrm{~nm})$, for a cycle of $30 \mathrm{~min}$ at room temperature. After polymerization, the capillaries containing the monolithic MIPs were connected to a nano-pump and rinsed thoroughly with several capillary volumes of ACN/acetic acid $(98 / 2, \mathrm{v} / \mathrm{v})$ to remove the template molecules and other residual reagents. The monolithic non-imprinted polymers (NIPs) were obtained by performing the same procedure in the absence of the template. The resulting capillaries from the thermal initiation were cut to obtain $50 \mathrm{~mm}$-long capillaries while those resulting from the UV irradiation were cut to obtain $100 \mathrm{~mm}$-long capillaries containing a 10, 25 or $50 \mathrm{~mm}$-long monolithic MIP having its extremity at $10 \mathrm{~mm}$ from the outlet.

\section{2-4 Characterization of the monoliths by scanning electron microscopy and nanoLC}

The cross section of the capillaries containing the polymer was observed by SEM, with a Quattro $S$ environmental scanning electron microscope (ThermoFisher Scientific, Le Pecq, France).

Permeability measurements were carried out with an Ultimate ${ }^{\mathrm{TM}}$ RSLCnano 3000 system (ThermoFisher Scientific, Le Pecq, France), composed of a nanoLC pump delivering $100 \%$ ACN $\left(\eta=0.316 \mathrm{mPa} s\right.$ at $35^{\circ} \mathrm{C}$ ) at a constant temperature of $35^{\circ} \mathrm{C}$ with different flow rates and allowing to record the generated back-pressure. The permeability was calculated using Darcy's law (Equation 1):

$$
\mathrm{K}=\frac{4 \eta \mathrm{LF}}{\pi \mathrm{d}_{\mathrm{i}}^{2} \Delta \mathrm{P}} \quad \text { (Equation 1) }
$$

$K$ is the permeability $\left(\mathrm{m}^{2}\right), \mathrm{F}$ the applied flow rate $\left(\mathrm{m}^{3} \mathrm{~s}^{-1}\right), \eta$ the viscosity of the solvent $(\mathrm{Pa} \mathrm{s}), \mathrm{L}$ the length of the capillary $(\mathrm{m}), \Delta \mathrm{P}$ the measured back-pressure $(\mathrm{Pa})$, and $\mathrm{d}_{\mathrm{i}}$ the capillary inner diameter (m).

For retention studies, cocaine $\left(5 \mu \mathrm{g} \mathrm{mL}^{-1}\right)$ and BZE $\left(5 \mu \mathrm{g} \mathrm{mL}^{-1}\right)$ were injected on the monolithic MIP or NIP contained in a capillary connected to a nanoLC system composed of a six-port switching nanovalve (Cheminert nanovolume 6 ports 2 pos 1/32", manual CN2-4346, Vici Valco Instruments Inc. Co., Houston, TX, USA) connected to a home-made injection loop $(50 \mathrm{~nL})$, to a nano-pump (NCP-3200RS Nano Pump, ThermoFisher Scientific Dionex, controlled by Chromeleon 6.80 SR12) and to a diode array detector (VWD 3100 Detector, ThermoFisher Scientific Dionex) with a flow cell of $3 \mathrm{~nL}$. The capillaries containing the MIP or NIP were maintained at $35^{\circ} \mathrm{C}$ with a column oven (TCC 3000SD column compartment, ThermoFisher Scientific Dionex). Compounds were detected at $233 \mathrm{~nm}$. The flow rate of ACN was set at $400 \mathrm{~nL} \mathrm{~min}{ }^{-1}$. The marker used to determine the dead volume was acetone. The retention factors $k$ and imprinting factors (IF) were calculated using the following equation 2 and equation 3 , respectively:

$$
\mathrm{k}=\frac{\mathrm{t}_{\mathrm{r}}-\mathrm{t}_{0}}{\mathrm{t}_{0}} \quad \text { (Equation 2) }
$$

where $t_{r}$ and $t_{0}$ are the retention times of cocaine or BZE and of acetone, respectively.

$$
\mathrm{IF}=\frac{\mathrm{k}_{\mathrm{MIP}}}{\mathrm{k}_{\mathrm{NIP}}} \quad \text { (Equation } 3 \text { ) }
$$

where $\mathrm{k}_{\mathrm{MIP}}$ and $\mathrm{k}_{\mathrm{NIP}}$ are the retention factors obtained on the MIP and NIP monolithic columns, respectively. 


\section{2-5 On-line coupling of MIP extraction with nanoLC-UV}

Preliminary studies were performed with the on-line set-up previously designed [40] and allowing the coupling of a monolithic MIP/NIP thermally synthesized to a nanoLC-UV device as presented in Figure S1. Briefly, a syringe pump (Standard Infuse/Withdraw PHD ULTRA ${ }^{\mathrm{TM}} 4400$ Programmable Syringe Pump, Harvard apparatus, Les Ulis, France) was connected to a six-port switching nano-valve (valve 1). Valve 1 was connected to an injection loop and to a second six-port switching nano-valve (valve 2). The MIP or NIP (50 mm x $100 \mu \mathrm{m}$ i.d.) associated with an empty capillary ( $80 \mathrm{~mm} \times 26 \mu \mathrm{m}$ i.d., see Figure S2 A) were connected at the loop position of valve 2 . This valve was also connected to a nanoLC pump (Ultimate ${ }^{\mathrm{TM}}$ NanoFlow RSLC system, ThermoFisher Scientific Dionex) and to a nanoLC analytical column (Acclaim ${ }^{\mathrm{TM}}$ PepMap $^{\mathrm{TM}} 100 \mathrm{C} 18,150 \times 0.075 \mathrm{~mm}, 3 \mu \mathrm{m}$, ThermoFisher Scientific).

In the first step of the extraction procedure, $50 \mathrm{~nL}$ of sample were transferred from the loop to the monolithic MIP/NIP capillary using $1,000 \mathrm{~nL}$ of a $\mathrm{H}_{2} \mathrm{O} / \mathrm{ACN}(90 / 10, \mathrm{v} / \mathrm{v})$ mixture, delivered by the syringe pump at a flow rate of $200 \mathrm{~nL} \mathrm{~min}$. The valve 2 was then switched allowing the elution of the trapped compounds from the monolithic MIP/NIP to the nanoLC analytical column by the mobile phase delivered by the nanoLC pump at $200 \mathrm{~nL} \mathrm{~min}^{-1}$, i.e. ammonium formate $10 \mathrm{mM} \mathrm{pH} 3.1$ adjusted with formic acid (A) and ACN (B). The gradient started with $10 \% \mathrm{~B}$, increased to $25 \% \mathrm{~B}$ in $1.5 \mathrm{~min}$, then reached $40 \%$ B in $5.6 \mathrm{~min}$, increased to $80 \% \mathrm{~B}$ in $0.8 \mathrm{~min}$, and remained for $2.4 \mathrm{~min}$. Finally, the composition of $B$ was set back to $10 \%$ to let the system equilibrate.

\section{2-6 On-line coupling of MIP extraction with UV detection}

The on-line set-up allowing the coupling of the extraction with the monolithic MIP or NIP directly to the UV detection is presented in Figure $1 \mathbf{A}$. The solution of transfer and washing, and next the elution solution were percolated owing to a nanoLC pump (Ultimate ${ }^{\mathrm{TM}}$ NanoFlow RSLC system) connected to valve 1 and valve 2 . Valve 1 was connected to home-made injection loops (150,300, or $600 \mathrm{~nL})$ and to valve 2. Valve 2 was connected to the capillary containing either the MIP or NIP and to the UV detector. For the $50 \mathrm{~mm}$-long capillary filled with the MIP or NIP obtained by thermal initiation, it was associated with an empty capillary ( $80 \mathrm{~mm} \times 26 \mu \mathrm{m}$ i.d.) downstream of them to allow their connection to the valve as presented in Figure $\mathbf{1}$ B1. (see for more details Figure S2 A). For monoliths synthesized by photopolymerization, the monolith was $10 \mathrm{~mm}$-long and has its extremity at $10 \mathrm{~mm}$ from the outlet of a $100 \mathrm{~mm} \times 100 \mu \mathrm{m}$ capillary (see for more details Figure S2 B). Two positions of the capillary containing the monolithic MIP/NIP on the valve 2 were studied, as shown in the Figures $\mathbf{1}$ B2 and $\mathbf{1} \mathbf{B 3}$. All other connections were achieved with $26 \mu \mathrm{m}$ i.d. fused-silica capillaries (Polymicro Technologies, $360 \mu \mathrm{m}$ o.d.) and microtight unions PEEK (Upchurch Scientific).

In the first step of the extraction procedure, sample was loaded into the loop (150-600 nL) (valve 1). In parallel, the nanoLC pump connected to valve 1 allows the conditioning of the monolith with a $\mathrm{H}_{2} \mathrm{O} / \mathrm{ACN}(90 / 10, v / v)$ mixture. Then, valve 1 was switched in order to transfer the sample to the monolithic MIP/NIP for extraction using the transfer/washing solution through the sample loop at a flow rate of $400 \mathrm{~nL} \mathrm{~min}{ }^{-1}$ with a volume that was varied between 900 and 1,750 $\mathrm{nL}$ (optimized value used for applications: 1,300 $\mathrm{nL}$ ). In a second step, the nanoLC pump was connected to the valve 2 and the detector was conditioned with a solution of $\mathrm{H}_{2} \mathrm{O} / \mathrm{ACN}(70 / 30, \mathrm{v} / \mathrm{v})$. At the last step, the valve 2 was switched allowing thus the back-flush elution of the trapped compounds from the monolithic MIP/NIP to the UV detector by the $\mathrm{H}_{2} \mathrm{O} / \mathrm{ACN}(70 / 30, \mathrm{v} / \mathrm{v})$ mixture. After each analysis, the MIP/NIP monolith was re-conditioned with the initial $\mathrm{H}_{2} \mathrm{O} / \mathrm{ACN}$ mixture $(90 / 10, v / v)$, that was used for the

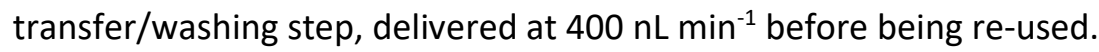

During each step of the analytical cycle, it was checked that the pressure applied on the monolith was constant. Nevertheless, an additional pressure of 2 bar was observed during each transfer step from valve 1 to valve 2 corresponding to the pressure generated by the injection loop. Similarly, an additional pressure of 5 bar was observed during the elution/detection step due to the UV cell and its connection capillaries. 
A

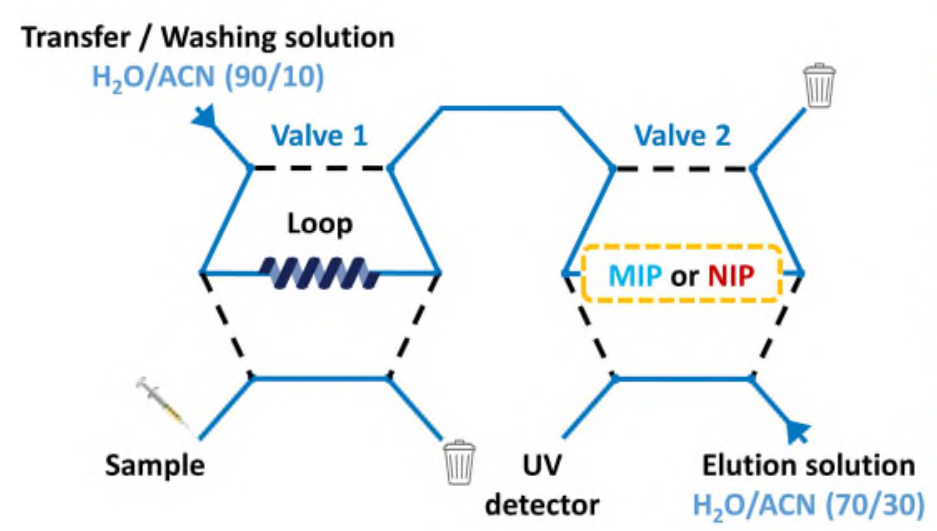

B

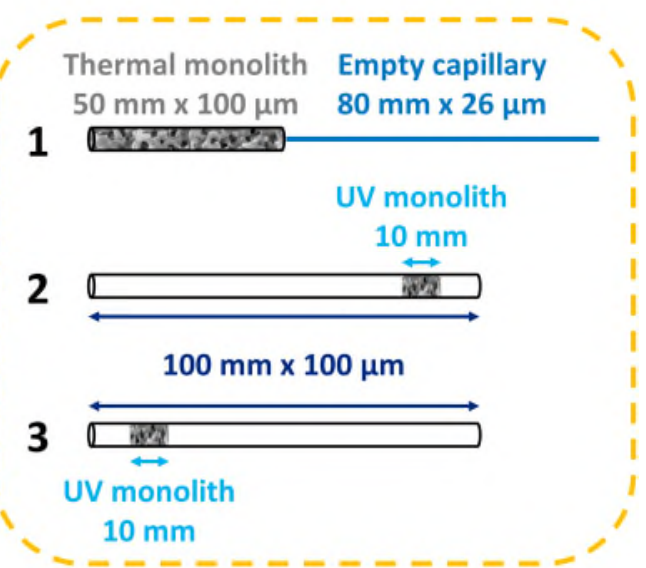

Figure 1. (A) Set-up allowing the on-line coupling of the MIP/NIP directly to UV detection; (B) mode of connection of the MIP/NIP capillary to the valve: monolithic MIP/NIP obtained by $(1)$ thermal or $(2,3)$ UV initiation of the polymerization.

\section{2-7 Preparation of biological samples}

Urine samples were collected from a healthy individual and were free of cocaine and BZE. $500 \mu \mathrm{L}$ of urine were diluted with $\mathrm{H}_{2} \mathrm{O}(\mathrm{x} 2)$, next filtered with $0.45 \mu \mathrm{m}$ pore size Millex ${ }^{\circledR}$ syringe filters from Merck (Darmstadt, Germany) and stored at $-20^{\circ} \mathrm{C}$ until use. The diluted and filtered urine samples were either directly analyzed or spiked with BZE to obtain a concentration of $150 \mathrm{ng} \mathrm{mL}^{-1}$ in the diluted sample, which corresponds to $300 \mathrm{ng} \mathrm{mL}^{-1}$ in urine. A volume of $600 \mathrm{~nL}$ was analyzed by SPE on MIP or NIP and UV detection.

\section{Results and discussion}

\section{3-2 Preliminary study on the potential of an on-line MIP-UV set-up for the analysis of BZE}

The objective was to make the most of the selectivity provided by a monolithic MIP for a target molecule in order to couple MIP directly with UV detection for the simplified analysis of the target in a complex sample without resorting to an intermediate separation step. BZE, the main urinary metabolite of cocaine, was taken as model molecule for this study with the ultimate goal of detecting it at trace amounts in urine, itself chosen as a complex model matrix. For the synthesis of the MIP, cocaine was taken as template, the use of a dummy molecule preventing from the risk of false positive caused by template leakage when applying the MIP to real samples. Moreover, in a previous study, a cocaine imprinted poly(MAA-co-TRIM) monolith was in situ polymerized using cocaine as template in a fused-silica capillary $\left(50 \mathrm{~mm} \times 100 \mu \mathrm{m}\right.$ i.d.) by thermal initiation at $60^{\circ} \mathrm{C}$ for $24 \mathrm{~h}$, leading to imprinting factors of $3.2 \pm 0.5$ for cocaine but also of $2.2 \pm 0.3$ for BZE demonstrating the possibility to retain the latter specifically on the MIP imprinted with cocaine [40]. Furthermore, the use of BZE as template for MIP synthesis appeared to be complicated as it is only commercially available in solvents such as $\mathrm{MeOH}$ or water, that are protic solvents preventing the development of hydrogen bonds between the monomer and the template which are necessary during the polymerization step to give rise to specific cavities. Therefore, the synthesis conditions of the MIP imprinted with cocaine previously described were selected to synthesize new monoliths dedicated to BZE here.

To check their retention property, they were placed at a loop position of a six-port switching valve to be connected to an injection loop and to the nanoLC-UV system (see set-up in Figures S1 and S2 A) as in the previous study [40].The extraction procedure previously optimized to promote BZE retention on the MIP while decreasing its retention on the NIP in order to obtain an optimal selectivity was applied. A volume of $50 \mathrm{~nL}$ of water spiked with BZE at $1 \mu \mathrm{g} \mathrm{mL} \mathrm{m}^{-1}$ was injected followed by a transfer/washing 
step using $1,000 \mathrm{~nL}$ of a mixture of $\mathrm{H}_{2} \mathrm{O} / \mathrm{ACN}(90 / 10, \mathrm{v} / \mathrm{v})$, the elution being further ensured by the nanoLC mobile phase to elute BZE from the monolith to the analytical column. With these conditions, the same results were obtained for BZE as it was totally recovered on the MIP and the extraction recovery was only $25 \%$ on the NIP. Those preliminary results confirmed the repeatability of the MIP synthesis and its selectivity towards BZE. This MIP was therefore adapted for studying the development of a simplified analytical set-up without any analytical column.

A two-valve set-up was then designed as described in Figure $1 \mathbf{A}$. It involves a sample loop connected to valve 1 and the capillary containing the MIP or NIP connected to valve 2 . Due to instrumental constraints making the length of the capillary entirely filled by the monolith $(50 \mathrm{~mm})$ insufficient to connect the two ports of valve 2 , this capillary was associated with an empty capillary ( $80 \mathrm{~mm} \times 26 \mu \mathrm{m}$ i.d.) downstream of it to allow its connection (see Figure $\mathbf{1}$ B1 and Figure S2 A for detailed description of the connecting tools). A higher volume of $150 \mathrm{~nL}$, instead of $50 \mathrm{~nL}$ previously used, of water spiked with BZE at $10 \mu \mathrm{g} \mathrm{mL}^{-1}$ was introduced in the loop in order to prevent detection limit problems caused by the removal of the analytical column and thus the lack of concentration effect of the elution fraction at the top of the column. Consequently, the volume of the transfer/washing solution $\left(\mathrm{H}_{2} \mathrm{O} / \mathrm{ACN}, 90 / 10\right.$, $\mathrm{v} / \mathrm{v}$ ) was reduced from $1,000 \mathrm{~nL}$ to $900 \mathrm{~nL}$ in order to maintain a constant volume adding the volumes of the sample and of the transfer/washing solution flowing through the monolith. Finally, a back-flush elution towards the UV detector of the analytes fixed on the monolith was performed with a $\mathrm{H}_{2} \mathrm{O} / \mathrm{ACN}$ $(70 / 30, v / v)$ mixture. The chromatograms resulting from this procedure applied in triplicate on the MIP and NIP are shown in Figure 2. Focusing on repeatability, the peak heights have low RSD values of 2.0 and $9.3 \%(n=3)$ for MIP and NIP, respectively. Average peak heights of 4.83 and 0.43 mAU were obtained for the MIP and NIP, respectively. The selectivity of the MIP toward BZE is thus confirmed with a peak height more than 11 times higher using the imprinted monolith than using the nonimprinted one.

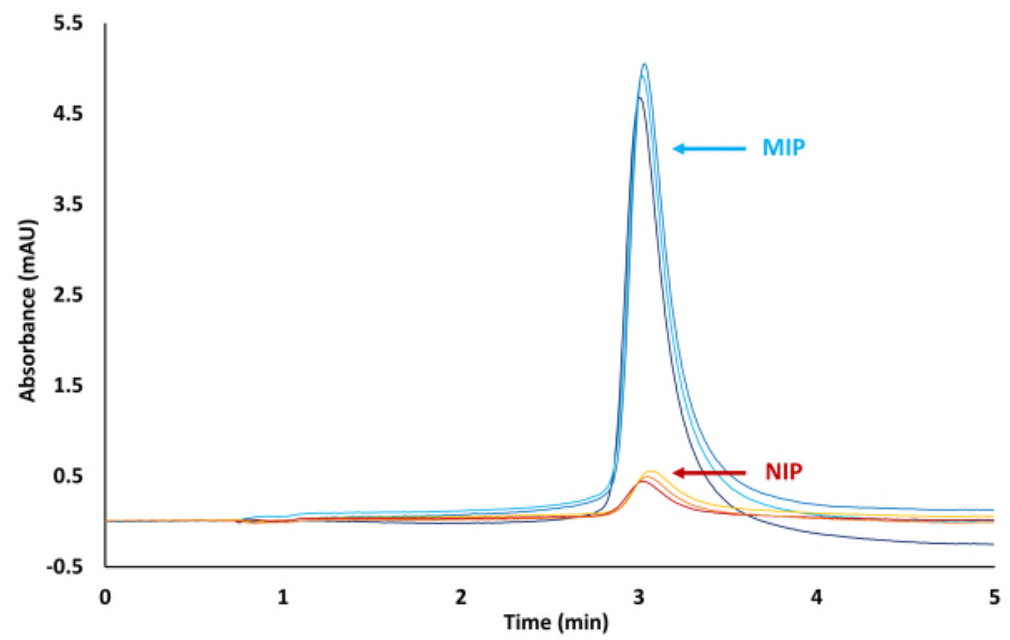

Figure 2. Chromatograms obtained with the direct on-line coupling of the monolithic MIP/NIP (50 mm x $100 \mu \mathrm{m})$ synthesized by thermal initiation with UV detection. $V_{\text {inj }}=150 \mathrm{~nL}$ (BZE at $10 \mu \mathrm{g} \mathrm{mL}^{-1}$ in water), Transfer/washing solution: $900 \mathrm{~nL}$ of $\mathrm{H}_{2} \mathrm{O} / \mathrm{ACN}(90 / 10, \mathrm{v} / \mathrm{v})$, UV detection at $233 \mathrm{~nm}$. Other conditions: see Section 2.5.

Despite the high selectivity obtained, the lengths of the monoliths used could still be considered too long to develop miniaturized extraction systems. As a 10-fold decrease in peak height, i.e. $0.43 \mathrm{mAU}$, was obtained by injecting the same spiked sample but diluted 10 times $\left(1 \mu \mathrm{g} \mathrm{mL}^{-1}\right)$ on the MIP, the capacity of the $50 \mathrm{~mm}$-long monolithic MIP did not seem to be reached when percolating a concentrated sample $\left(10 \mu \mathrm{g} \mathrm{mL}^{-1}\right)$. It was therefore considered to reduce the length of the monolith. Although it is possible to cut a capillary completely filled with a monolith to the desired length, it is however impossible to connect it to a valve, in place of the loop, even using an empty capillary as before because of the minimum length of tubing required for liners, as shown in Figure S2. It was therefore necessary to develop another approach based on the use of a single capillary partially filled with a monolith over a controlled length. This can be achieved by initiating the polymerization under 
UV and using mask to get a monolith of the expected length and thus avoiding connection issues, as shown in Figure S2 B. Another significant advantage provided by photopolymerization is the reduction of the synthesis time since thermal initiation was previously performed for $24 \mathrm{~h}$ while the UV exposure was only performed for few minutes or hours. However, since the MIP synthesis conditions were modified, it was necessary to verify the characteristics of the monolith in terms of synthesis repeatability, permeability, and selectivity.

\section{3-3 Study of the synthesis conditions}

To limit the template consumption, preliminary evaluations of the effect of exposure time to UV irradiation $(15,30,60$ or $120 \mathrm{~min}$ ) on the resulting monoliths were carried out by synthesizing one NIP for each photopolymerization time. Therefore, they were prepared using the same polymerization reagents as for thermal initiation (MAA, TRIM, and ACN containing $10 \%$ isooctane with a $\mathrm{M} / \mathrm{CL}$ ratio of $1 / 5(\mathrm{~mol} / \mathrm{mol})$ and a $(\mathrm{M}+\mathrm{CL}) / \mathrm{P}$ ratio of $15 / 85(\mathrm{v} / \mathrm{v}))$ introduced in $150 \mathrm{~mm}$-long capillaries $(100 \mu \mathrm{m}$ i.d.). Masks with windows of different lengths, i.e. 10, 25, or $50 \mathrm{~mm}$, were used, while ensuring that the window was at a minimum of $10 \mathrm{~mm}$ from a capillary end. After the monolith synthesis, the capillaries were then cut to a length of $100 \mathrm{~mm}$, with the monolith still being at $10 \mathrm{~mm}$ from one extremity. The back-pressure generated by each capillary, maintained at $35^{\circ} \mathrm{C}$, was then measured while pumping

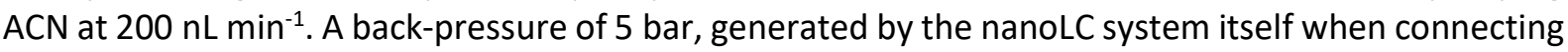
a $100 \mathrm{~mm}$-long empty capillary, was subtracted from the back-pressure value measured when connecting the capillary containing the monolith.

For a polymerization time of $15 \mathrm{~min}$, back-pressure values of 5, 9, and 34 bar were obtained for monolithic NIPs of 10, 25, and $50 \mathrm{~mm}$, respectively. Those values were significantly lower than the ones obtained for longer exposure times whatever the length of the monolith, indicating that polymerization was incomplete or that the monolith was incorrectly attached to the capillary inner surface. This was confirmed by SEM observations (Figure S3 A). Indeed, it appears on the pictures that the monolithic NIP synthesized with a UV irradiation of only $15 \mathrm{~min}$ did not occupy the entire section of the capillary, indicating incomplete polymerization. In return, the monoliths synthesized with $30 \mathrm{~min}$ of UV exposure occupied the whole section of the capillary and were well anchored to its surface (Figure S3 B). It is worthwhile to notice that identical SEM observations can be made for the thermally synthesized NIP (Figure S3 C). Concerning the exposure times of 30, 60, and $120 \mathrm{~min}$, the same backpressure value of 7 bar was measured for the monolithic NIPs of $10 \mathrm{~mm}$. In addition, back-pressure values of 17, 15, and 20 bar were obtained for $25 \mathrm{~mm}$-long NIPs, whereas values of 43,40 , and 54 bar were obtained for $50 \mathrm{~mm}$-long NIPs with polymerization time of 30,60 , and $120 \mathrm{~min}$, respectively. In summary, average values of $7 \pm 0,17 \pm 3$, and $46 \pm 7$ bar were measured for monolithic lengths of 10 , 25 , and $50 \mathrm{~mm}$, respectively, whatever the polymerization time value of 30,60 , or $120 \mathrm{~min}$. These results suggested that polymerization was complete after only $30 \mathrm{~min}$ of UV irradiation, and this duration was retained for the rest of the study.

These preliminary experiments related to NIPs were followed by three independent syntheses of MIPs and NIPs for each of the three lengths, with a UV irradiation time of $30 \mathrm{~min}$. The same observations of occupation of the whole section of the capillary and good anchoring to its surface were made for the SEM images of the MIPs as for the corresponding NIPs discussed above (Figure S3).

The permeability of the monoliths was estimated by applying various flow rates of ACN. Knowing $\eta$, the permeability can be deduced from $\Delta \mathrm{P}$ measurements as explained in Section 2.3. The results obtained are reported in Table 1. First of all, the permeability of NIP was always higher than that of MIP thus showing the effect of the presence of the template molecule during the polymerization on the structure of the resulting monoliths. Moreover, RSD values of permeability were between 2 and $19 \%(n=3)$, indicating a satisfactory repeatability of the synthesis whatever the length of the monolith. Subsequently, one-factor variance analyses were performed to assess the impact of the length $(10,25$, or $50 \mathrm{~mm}$ ) on the permeabilities of either MIP or NIP monoliths. No significant differences were observed (ANOVA, $p$ value $=0.83>0.05$ and $0.49>0.05$ for MIP and NIP, respectively). Finally, the average permeabilities were $0.65 \times 10^{-15} \mathrm{~m}^{2}(\mathrm{RSD}=8 \%, \mathrm{n}=9)$ and $1.67 \times 10^{-15} \mathrm{~m}^{2}(\mathrm{RSD}=13 \%, \mathrm{n}=9)$ for 
the MIPs and NIPs obtained under UV irradiation, respectively. Comparing these values with those obtained by thermal initiation with the same reagents, a five-fold lower permeability can be observed for photopolymerized MIPs. As a direct consequence, the monolithic MIPs with a length of $50 \mathrm{~mm}$ generated a back-pressure of $105 \pm 3$ bar for a flow rate of $200 \mathrm{~nL} \mathrm{~min}{ }^{-1}$. In order to limit excessive back-pressure preventing the future replacement of expensive nanoLC pumps by less expensive syringe pumps, only monolithic MIPs and NIPs having a length of 10 and $25 \mathrm{~mm}$ were therefore selected for further investigations.

Table 1. Permeabilities measured on MIPs and NIPs obtained by photo-initiation for 30 min and comparison with permeability values of monoliths obtained by thermal initiation using the same reagents [40] (three syntheses for each length).

\begin{tabular}{|c|c|c|c|c|c|}
\hline & $\begin{array}{l}\text { Monolithic length } \\
(\mathrm{mm})\end{array}$ & $\begin{array}{l}\mathrm{K}\left(10^{-}\right. \\
\left.{ }^{15} \mathrm{~m}^{2}\right)\end{array}$ & RSD, $n=3(\%)$ & $\begin{array}{c}\mathrm{K} \\
\text { average } \\
\left(10^{-15} \mathrm{~m}^{2}\right)\end{array}$ & RSD, $n=3(\%)$ \\
\hline \multirow{3}{*}{ MIP (UV initiation) } & 10 & 0.63 & 14 & \multirow{3}{*}{0.65} & \multirow{3}{*}{8} \\
\hline & 25 & 0.66 & 6 & & \\
\hline & 50 & 0.64 & 2 & & \\
\hline $\begin{array}{c}\text { MIP (Thermal initiation) } \\
{[40]}\end{array}$ & 50 & 3.27 & 3 & - & - \\
\hline \multirow{3}{*}{$\begin{array}{c}\text { NIP } \\
\text { (UV initiation) }\end{array}$} & 10 & 1.72 & 19 & \multirow{3}{*}{1.67} & \multirow{3}{*}{13} \\
\hline & 25 & 1.75 & 11 & & \\
\hline & 50 & 1.54 & 3 & & \\
\hline $\begin{array}{c}\text { NIP (Thermal initiation) } \\
{[40]}\end{array}$ & 50 & 36.57 & 17 & - & - \\
\hline
\end{tabular}

\section{3-4 Evaluation of the selectivity studying retention properties in nanoLC}

The selectivity of the MIPs obtained by photopolymerization was then studied by measuring the retention of BZE and cocaine (template molecule) on MIPs and NIPs. For this, monolithic MIPs/NIPs were used as a separation column directly connected to UV detection. Each compound solution $(50 \mathrm{~nL}$, $5 \mu \mathrm{g} \mathrm{mL}^{-1}$ ) was injected on each MIP and its corresponding NIP having a length of 10 or $25 \mathrm{~mm}$. The injection of acetone on each monolith allowed the determination of the $t_{0}$ value and then the calculation of the retention and imprinted factors. The evaluation was carried out using ACN as mobile phase because, as often mentioned in literature, the selectivity of the retention should be optimal when the solvent used is close to the porogen, i.e. ACN containing $10 \%$ isooctane here. Moreover, the cocaine imprinted poly(MAA-co-TRIM) monolith previously prepared by thermal polymerization was very selective towards cocaine and BZE in this solvent [40].

As an example, the chromatograms obtained for a $10 \mathrm{~mm}$-long MIP and its corresponding NIP are provided in Figure 3Erreur! Source du renvoi introuvable.. These chromatograms clearly illustrate the stronger retention of both molecules on MIP than on NIP. IF values measured on MIPs and their corresponding NIPs from three independent syntheses for the two different monolith lengths are reported in Table 2 and compared with values previously obtained for the MIP and NIP polymerized by thermal initiation [40]. The template cocaine is more retained on MIPs than on the corresponding NIPs giving rise to IF values above 3 , independently of the length of the monolith, thus attesting the presence of cavities specific to cocaine in MIPs and also the homogeneity of the monolithic MIP along its entire length. In addition, as for the MIP obtained by thermal initiation, these cavities are also able to selectively retain BZE, since imprinted factors higher than 2 were obtained. These results confirmed that both thermal- and photopolymerization modes can give MIPs with specific cavities. Moreover, 
RSD values of IFs for cocaine and BZE measured on MIPs resulting from three independent synthesis were lower than $14 \%$, which confirmed the repeatability of the synthesis procedure already demonstrated by the permeability measurements, despite the broad shape of the peaks that has a strong impact on measurement accuracy.

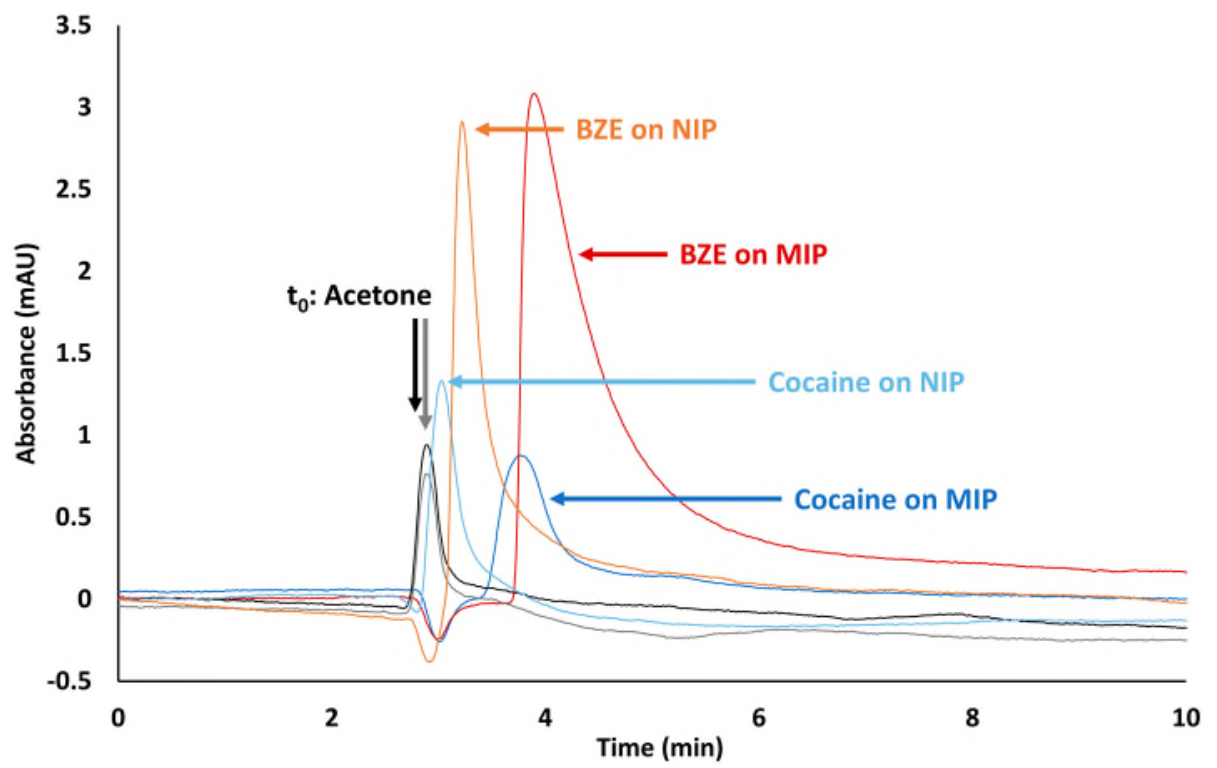

Figure 3. Chromatograms obtained after the injection of acetone, cocaine $\left(5 \mu \mathrm{g} \mathrm{mL}^{-1}\right)$, or BZE $\left(5 \mu \mathrm{g} \mathrm{mL}^{-1}\right)$ on monolithic MIP and NIP $(10 \mathrm{~mm} \times 100 \mu \mathrm{m}$ i.d.) synthesized under UV for $30 \mathrm{~min}$ in a $100 \mathrm{~mm} \times 100 \mu \mathrm{m}$ i.d. capillary. $V_{\text {inj }}=50 \mathrm{~nL}$, Mobile phase: $A C N$ at $400 \mathrm{~nL} \mathrm{~min}^{-1}$, UV detection at $233 \mathrm{~nm}$.

Table 2. Imprinted factors of cocaine and BZE measured on three different MIPs and NIPs polymerized by UV or thermal initiation [40]. Experimental conditions: see legend of Figure 3Erreur ! Source du renvoi introuvable..

\begin{tabular}{|c|c|c|c|c|c|c|}
\hline & \multicolumn{2}{|c|}{$\begin{array}{c}\text { Monolith (10 mm, UV } \\
\text { irradiation) }\end{array}$} & \multicolumn{2}{c|}{$\begin{array}{c}\text { Monolith }(25 \mathrm{~mm}, \mathrm{UV} \\
\text { irradiation) }\end{array}$} & \multicolumn{2}{c|}{$\begin{array}{c}\text { Monolith (50 mm, thermal } \\
\text { initiation) [40] }\end{array}$} \\
\hline & $\mathrm{IF}$ & $\mathrm{RSD}, \mathrm{n}=3(\%)$ & $\mathrm{IF}$ & $\mathrm{RSD}, \mathrm{n}=3(\%)$ & $\mathrm{IF}$ & $\mathrm{RSD}, \mathrm{n}=3$ (\%) \\
\hline BZE & 2.6 & 2 & 2.8 & 5 & 2.2 & 13 \\
\hline Cocaine & 3.7 & 14 & 4.3 & 13 & 3.2 & 17 \\
\hline
\end{tabular}

In addition, for the monoliths obtained by photopolymerization, a one-factor variance analysis was performed to evaluate the potential impact of the monolith length ( 10 or $25 \mathrm{~mm}$ ) on IF values of cocaine and BZE. No significant differences were observed (ANOVA, $p$ value $=0.28>0.05$ and $0.07>0.05$ for cocaine and BZE, respectively), resulting in final average IF values of $4.0 \pm 0.6$ and $2.7 \pm 0.1$ for cocaine and BZE, respectively. Considering then the influence of the initiation mode (thermal or UV) on the IFs, one-factor variance analyses were also carried out. For cocaine there is no significant difference between the two initiation modes (ANOVA, $p$ value $=0.09>0.05$ ), whereas there is a significant difference for BZE (ANOVA, $p$ value $=0.006<0.05$ ), demonstrating the selectivity enhancement for BZE of the monolithic MIPs obtained by photopolymerization.

\section{3-5 Optimization of the on-line MIP extraction and UV detection analysis protocol}

After having demonstrated the selectivity of the monolithic MIP using it as a separation column, a new set-up was developed to use it as an extraction sorbent and to couple it on-line directly with UV detection. The capillary (100 mm x $100 \mu \mathrm{m}$ i.d.) containing the monolithic MIP or NIP was placed at the loop position of a valve (valve 2 ) and connected between another valve where is the sample injection loop (valve 1) and the UV detector as shown in Figure $\mathbf{1} \mathbf{A}$. This set-up allowed a back-flush elution of 
the compounds trapped from the monolith to the UV detector, thus limiting band broadening. To limit the elution volume required for the desorption and then the peak width, the shortest monoliths of $10 \mathrm{~mm}$-long were selected. It was first chosen to not place the monolith on the side of the injection loop (configuration Figure $\mathbf{1}$ B2) to limit the dilution of the eluting solution with the transfer/washing solution present in the void volume. The sample loaded in the loop $(150 \mathrm{~nL})$ was transferred by an $\mathrm{H}_{2} \mathrm{O} / \mathrm{ACN}(90 / 10, \mathrm{v} / \mathrm{v})$ mixture to the monolith, i.e. the mixture used in the preliminary tests with the monoliths synthesized by thermal polymerization. To estimate the volume required to transfer the sample from the loop to the monolith and do the washing, a calculation was performed, taking into account the difference in dead volume between the injection loop and the MIP for the current set-up and the one previously used in Section 3.1. Given the transfer/washing volume of $900 \mathrm{~nL}$ previously applied when using the MIP obtained by thermal initiation, a minimal volume of $1,230 \mathrm{~nL}$ has to be applied in this new set-up. Different other volumes were tested $(1,400,1,600$, and 1,800 nL) and a decrease in the BZE peak height was only observed with a volume of $1,800 \mathrm{~nL}$, indicating that the breakthrough volume was reached thus causing a decrease in recovery. Finally, it was possible to increase this transfer/washing volume up to $1,750 \mathrm{~nL}$ with no impact on the peak height for BZE $\left(150 \mathrm{~nL}, 1 \mu \mathrm{g} \mathrm{mL}^{-1}\right.$ in water) using the monolithic MIP. This higher volume of transfer/washing confirmed an improvement in retention provided by the monolithic MIP obtained by photopolymerization.

For the back-flush elution of BZE from the monolith to UV detection, a $\mathrm{H}_{2} \mathrm{O} / \mathrm{ACN}(70 / 30, \mathrm{v} / \mathrm{v})$ mixture was used as in the preliminary study. A chromatogram obtained by the on-line coupling of MIP extraction with direct UV detection for the analysis of BZE (150 nL, $1 \mu \mathrm{g} \mathrm{mL}^{-1}$ in water, transfer with $1,750 \mathrm{~nL}$ of washing solution) is presented Figure S4 A. A peak height of $0.45 \mathrm{mAU}$ was observed that is in good agreement with the value of $0.43 \mathrm{mAU}$ previously obtained in Section 3.1 when analyzing the same sample concentration with the $50 \mathrm{~mm}$ thermally-initiated monolithic MIP.

In order to increase the sensitivity of this method, the injected volume was increased. Volumes of 300 and $600 \mathrm{~nL}$ containing BZE at $1 \mu \mathrm{g} \mathrm{mL}^{-1}$ were then percolated through the monolithic MIP, while still adapting the volume of the transfer/washing solution in each extraction protocol to ensure that the overall volume (sample plus transfer/washing solution) flowing through the monolithic MIP was kept constant. Volumes of the transfer/washing solution of 1,600 and 1,300 nL were therefore used, respectively, and the chromatograms obtained are presented in Figure $\mathbf{S 4} \mathbf{A}$ together with the chromatogram corresponding to an injected sample of $150 \mathrm{~nL}$. The BZE peak height increase shows a linearity with respect to the injection volume $\left(R^{2}=0.998\right)$, indicating that the capacity of the monolithic MIP was not reached despite its reduced length $(10 \mathrm{~mm})$. An injected sample volume of $600 \mathrm{~nL}$ was therefore selected for subsequent analyses.

The selectivity of the monolithic MIP was then investigated by studying the retention of BZE on the corresponding NIP under the same conditions. Water spiked at $1 \mu \mathrm{g} \mathrm{mL}^{-1}$ with BZE was introduced in the injection loop of $600 \mathrm{~nL}$ and next transferred on the monolithic MIP or NIP with a volume of $1,300 \mathrm{~nL}$ of $\mathrm{H}_{2} \mathrm{O} / \mathrm{ACN}(70 / 30, \mathrm{v} / \mathrm{v})$. The resulting chromatograms demonstrated that this procedure promoted BZE retention on the MIP while giving rise to a low retention on the NIP (Figure S4 B). Indeed, peak heights of 1.80 and 0.25 mAU were obtained on the MIP and NIP, respectively. A factor of more than 7 in peak height was therefore obtained between the two supports confirming the selectivity brought by the specific cavities of the monolithic MIP.

Finally, the position of the monolith on the valve was investigated. Indeed, in the current position (configuration Figure $\mathbf{1}$ B2), the analytes retained on the MIP must flow through a large volume of empty capillary ( $80 \mathrm{~mm} \times 100 \mu \mathrm{m}$ i.d., $628 \mathrm{~nL}$ ) before reaching the detector during the elution step. By switching the capillary orientation and thus placing the monolith on the side of the injection loop (configuration Figure $1 \mathrm{B3}$ ), this volume can be reduced (10 mm x $100 \mu \mathrm{m}$ i.d., $79 \mathrm{~nL}$ ), which could have an influence on the shape of the peak. To assess this hypothesis, $300 \mathrm{~nL}$ of water spiked with BZE at $1 \mu \mathrm{g} \mathrm{mL} \mathrm{L}^{-1}$ was injected in both configurations. Once again, the volume of the transfer/washing solution was adapted to consider variations in dead volume. When the monolith was not implemented on the side of the injection loop (configuration Figure 1 B2), the transfer and washing were achieved with $1,600 \mathrm{~nL}$ while in the reversed position the volume applied was $1,050 \mathrm{~nL}$. The chromatograms obtained 
are reported in Figure $\mathbf{4} \mathbf{A}$. The shape and height of the peak do not seem to be affected by the position of the monolith in the valve. However, it will be important to confirm this observation by applying a much more complex sample, i.e. urine.
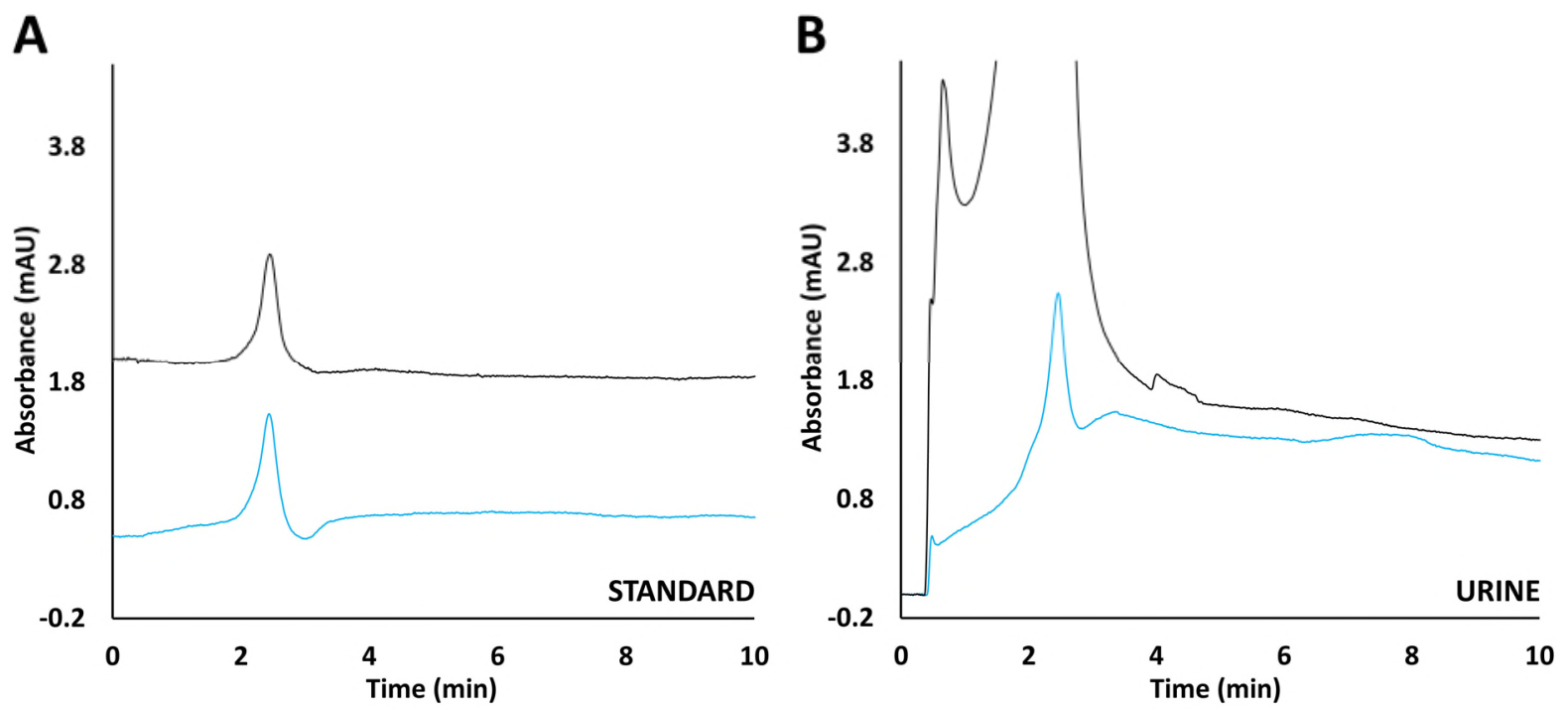

Figure 4. Chromatograms obtained after the analysis of $300 \mathrm{~nL}$ of $(A)$ water spiked with BZE at $1 \mu \mathrm{gL} \mathrm{m}^{-1}$ or (B) $2 \mathrm{x}$ diluted and filtered urine spiked with BZE at $1 \mu \mathrm{g} \mathrm{mL}^{-1}$ (equivalent to $2 \mu \mathrm{g} \mathrm{mL}^{-1}$ in urine) with the set-up implementing the monolithic MIP $(10 \mathrm{~mm} \times 100 \mu \mathrm{m}$ i.d.) on the side of the injection loop (configuration Figure 1 B3) (Black) or on the opposite side (configuration Figure 1 B2) (Blue). Transfer/washing step: 1,600 nL (Blue) or 1,050 nL (Black) of $\mathrm{H}_{2} \mathrm{O} / \mathrm{ACN}(90 / 10, \mathrm{v} / \mathrm{v})$. Other conditions: see Section 2.5.

\section{3-6 Applications to urinary samples}

The potential of the extraction/purification step with a monolithic MIP coupled on-line to UV detection was evaluated for the extraction of BZE from human urine samples. For this, urine was diluted twice with $\mathrm{H}_{2} \mathrm{O}$ and filtered. This sample was then spiked with BZE at $1 \mu \mathrm{g} \mathrm{mL}^{-1}$, which corresponds to a concentration level of $2 \mathrm{\mu g} \mathrm{mL}^{-1}$ in urine. In order to check the influence of the monolith position in the set-up, the same protocol as above was applied with an injection of $300 \mathrm{~nL}$ of sample, using the two possible configurations. The resulting chromatograms are presented in Figure $\mathbf{4} \mathbf{B}$.

While for spiked water no difference between the chromatograms was observed using both configurations, it was not the case when analyzing diluted urine. Indeed, when the monolith was positioned on the side of the injection loop (configuration Figure 1 B3), a huge peak of interfering compounds was observed, preventing the identification of BZE. In this configuration, the volume of transfer/washing solution $\left(1,050 \mathrm{~nL}\right.$ of $\left.\mathrm{H}_{2} \mathrm{O} / \mathrm{ACN}(90 / 10, \mathrm{v} / \mathrm{v})\right)$ was not sufficient to remove the interferents still present in the void volume of the empty capillary and that affect next the baseline of the chromatogram. In this position, even if there are no more interfering compounds retained on the MIP, these interferents are still present in the large volume of empty capillary ( $80 \mathrm{~mm} \times 100 \mu \mathrm{m}$ i.d., $628 \mathrm{~nL}$ ). Therefore, during back-flush elution, they were redirected to the monolithic MIP, without being retained owing to the elution strength of the solution containing $30 \% \mathrm{ACN}$, and then reached the UV detection cell.

On the other hand, when the monolith was not positioned on the side of the injection loop (configuration Figure 1 B2), the selectivity of the monolithic MIP allowed the removal of the interfering compounds present in urine and the $1,600 \mathrm{~nL}$ of transfer/washing solution were enough to carry the interfering analytes to waste. The resulting chromatogram exhibited a clean baseline with only one peak corresponding to BZE, similar to the one obtained with spiked water, thus showing no more matrix effect. This configuration was therefore selected for further applications with urinary samples. 
To evaluate the final potential of this on-line coupling, it was important to evaluate the concentration levels that could be quantified in urine samples. A French decree defines a positivity threshold of $300 \mathrm{ng} \mathrm{mL}^{-1}$ for the screening of BZE in urine [42]. Our goal was then to determine BZE at this low concentration level to comply with the current legislation. In this sense, to improve the sensitivity of the method, the $300 \mathrm{~nL}$ loop was replaced by the $600 \mathrm{~nL}$ loop. Urine samples spiked with three concentrations levels, i.e. 150,250 , and $500 \mathrm{ng} \mathrm{mL}^{-1}$ (equivalent to 300,500 , and $1,000 \mathrm{ng} \mathrm{mL}^{-1}$ in urine), were analyzed with the MIP-UV set-up using $1,300 \mathrm{~nL}$ of transfer/washing solution $\left(\mathrm{H}_{2} \mathrm{O} / \mathrm{ACN}\right.$, $90 / 10, v / v)$. BZE was back-flush eluted with the $\mathrm{H}_{2} \mathrm{O} / \mathrm{ACN}(70 / 30, \mathrm{v} / \mathrm{v})$ mixture. The resulting chromatograms are presented in Figure 5 A-C. A blank of urine was also analyzed in similar conditions (Figure $5 \mathrm{D}$ ). These chromatograms show that BZE can be easily detected for each concentration. Moreover, owing to the selectivity of the monolithic MIP, the baseline of the resulting chromatogram was cleaned of the majority of the interfering components from the biological matrix. The high selectivity of the monolithic MIP in this biological fluid was further demonstrated by injecting the highest concentrated urine sample ( $1 \mu \mathrm{g} \mathrm{mL}^{-1}$ in urine equivalent) on the monolithic NIP (Figure $5 \mathrm{E}$ ). The peak corresponding to BZE was not detected after extraction on the NIP, which highlighted again the selectivity of the MIP extraction procedure, these results being also consistent with those obtained previously in spiked water.

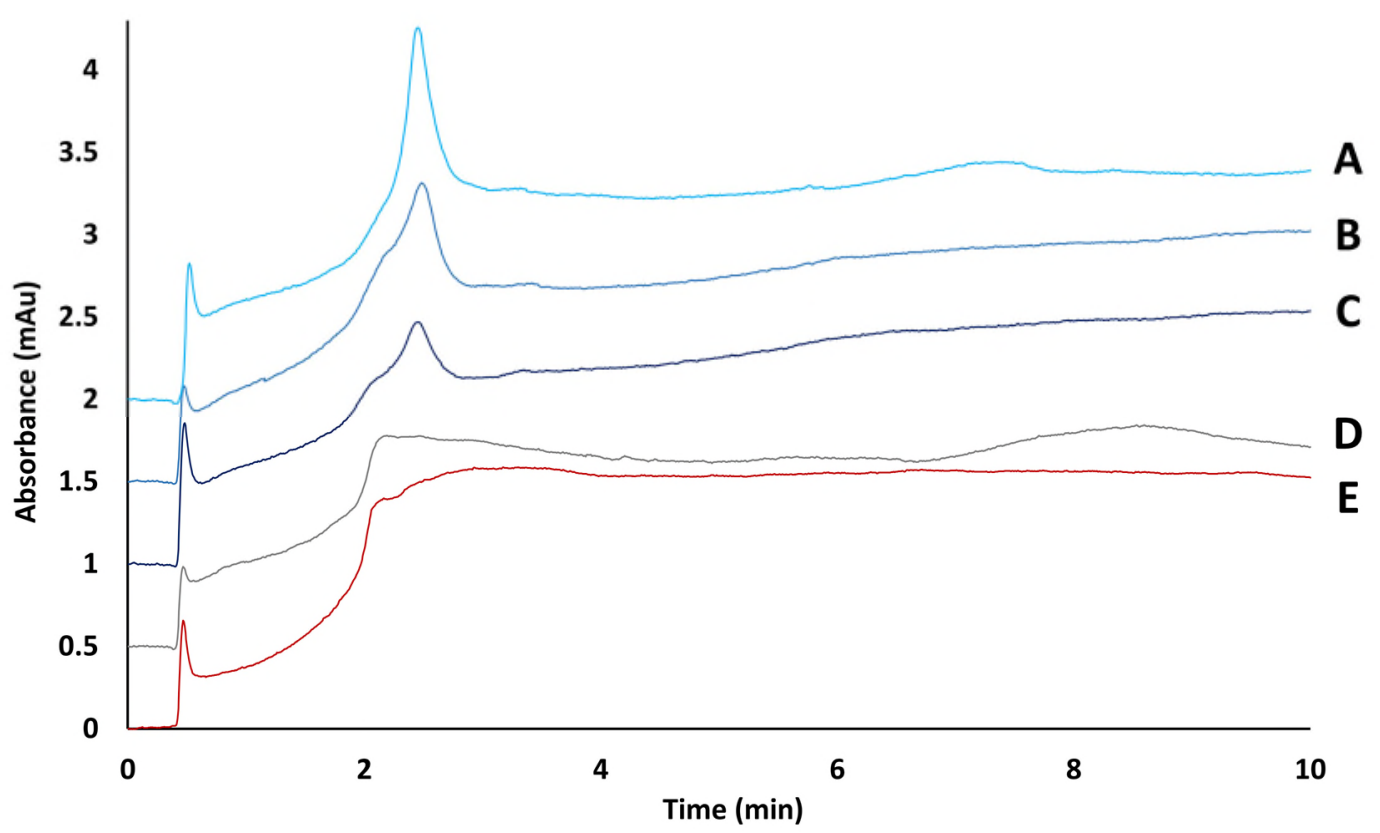

Figure 5. Chromatograms obtained after extraction on the monolith (10 mm x $100 \mu \mathrm{m}$ i.d.) coupled with UV detection of $600 \mathrm{~nL}$ of diluted urine (x2) spiked with BZE at (A) $500 \mathrm{ng} \mathrm{mL}^{-1}$, (B) $250 \mathrm{ng} \mathrm{mL}^{-1}$, and (C) $150 \mathrm{ng} \mathrm{mL}^{-1}$ or (D) non-spiked (blank) on MIP, and (E) of $600 \mathrm{~nL}$ of diluted urine (x2) spiked at $500 \mathrm{ng} \mathrm{mL}^{-1}$ on NIP. Transfer/washing step: 1,300 $\mathrm{nL}$ of $\mathrm{H}_{2} \mathrm{O} / \mathrm{ACN}(90 / 10, v / v)$. Configuration Figure 1 B2. Other conditions: see Section 2.5 .

The analytical performances were evaluated by analyzing urine samples spiked at 300,500 , and $1,000 \mathrm{ng} \mathrm{mL}^{-1}$ (concentration in urine equivalent) in triplicate on a MIP. Results are reported in Table 3. The curves plotting the peak height and area as a function of the BZE concentration in urine from 300 to $1,000 \mathrm{ng} \mathrm{mL}^{-1}$ (Figure S5) had a linear shape with $\mathrm{R}^{2}$ of 0.9999 and 0.9994 , respectively, thus indicating that the MIP capacity was not reached for these injected amounts. The LOD and LOQ were estimated for BZE, from the analysis of the sample spiked at $300 \mathrm{ng} \mathrm{mL}^{-1}$, at 56.4 and $188.0 \mathrm{ng} \mathrm{mL}^{-1}$ in urine equivalent, respectively. Therefore, it is possible to conclude that the developed approach fulfills the application requirements for the threshold established by the legislation. Focusing on repeatability, low RSD values $(n=3)$ were obtained for peak height $(2.1-6.3 \%)$ and peak area (2.1- 
4.4\%), for three analyses of this complex sample on one given monolithic MIP. At last, it can be noticed that more than 100 analyses of urine samples were achieved on one given monolithic MIP without observing any loss of performance. Moreover, no evolution of the back-pressure generated by the monolithic MIP was observed during the various analytical cycles, reflecting the conservation of its integrity in this on-line coupling.

Table 3. Analytical performances obtained for BZE in diluted (x2) urine spiked samples.

\begin{tabular}{|c|c|c|c|c|c|c|}
\hline $\begin{array}{c}\text { Spiked } \\
\text { concentration } \\
\left(\mathrm{ng} \mathrm{mL}^{-1}\right)^{*}\end{array}$ & $\begin{array}{c}\text { Average peak } \\
\text { height (mAU) }\end{array}$ & $\begin{array}{c}\text { RSD (peak } \\
\text { height), } \\
\mathrm{n}=3(\%)\end{array}$ & $\begin{array}{c}\text { Average area } \\
(\mathrm{mAU} \times \mathrm{min})\end{array}$ & $\begin{array}{c}\text { RSD (area), } \\
\mathrm{n}=3(\%)\end{array}$ & $\begin{array}{c}\text { LOD } \\
\left(\mathrm{ng} \mathrm{mL}^{-1}\right)\end{array}$ & $\begin{array}{c}\text { LOQ } \\
\left(\mathrm{ng} \mathrm{mL}^{-1}\right)\end{array}$ \\
\hline 300 & 0.32 & 6.3 & 0.064 & 4.4 & 56.4 & 188.0 \\
\hline 500 & 0.50 & 3.1 & 0.127 & 2.9 & - & - \\
\hline 1,000 & 0.96 & 2.1 & 0.302 & 2.1 & - & - \\
\hline
\end{tabular}

* Concentration in urine equivalent

\section{Conclusions}

In this work, the preparation of a monolithic MIP in a $100 \mu \mathrm{m}$ i.d. capillary by photopolymerization was studied as it allows, by applying adapted masks, the synthesis of monolithic MIPs of various lengths ( $\leq$ $50 \mathrm{~mm}$ ) in a longer capillary allowing to connect it on a valve. A simple set-up consisting of the MIP directly coupled on-line with a UV detector was implemented and further applied to the extraction of BZE from spiked urine samples (600 nL, $300 \mathrm{~nL}$ diluted twice). Various parameters were optimized, such as sample volume and position of the monolith in the set-up, and the resulting chromatograms showed very clean baselines. The repeatability of the analytical performances was assessed in urine samples and the legal threshold for the detection of BZE in urine was achieved for an overall analysis time of less than $10 \mathrm{~min}$.

These monolithic and miniaturized MIPs have proven to be an important contribution for the on-line selective determination of BZE. However, it would be possible to improve the set-up by implementing mass spectrometry detection instead of UV to improve the sensitivity of the device for real sample analysis and even differentiate other cocaine metabolites without being affected by the risk of matrix effects, the interfering compounds being nevertheless efficiently removed by the MIP. Another perspective in the continuity of all the progress made during this work is the integration of this technology into a microfluidic chip for the development of a lab-on-chip to provide a miniaturized and portable device. Indeed, during this work, the impact of connection dead volumes on the miniaturized system was highlighted. Therefore, a chip with a dedicated design integrating the different steps of the analysis would considerably reduce these issues.

\section{References}

[1] D.R. Reyes, D. Iossifidis, P.A. Auroux, A. Manz, Micro Total analysis systems. 1. Introduction, theory, and technology, Anal. Chem. 74 (2002) 2623-2636. https://doi.org/10.1021/ac0202435.

[2] A. Andrade-Eiroa, M. Canle, V. Leroy-Cancellieri, V. Cerdà, Solid-phase extraction of organic compounds: A critical review (Part I), TrAC Trends Anal. Chem. 80 (2016) 641-654. https://doi.org/10.1016/j.trac.2015.08.015.

[3] A. Andrade-Eiroa, M. Canle, V. Leroy-Cancellieri, V. Cerdà, Solid-phase extraction of organic compounds: A critical review. part II, TrAC Trends Anal. Chem. 80 (2016) 655-667. https://doi.org/10.1016/j.trac.2015.08.014.

[4] E.Z. Lee, Y.S. Huh, Y.S. Jun, H.J. Won, Y.K. Hong, T.J. Park, S.Y. Lee, W.H. Hong, Removal of bovine serum albumin using solid-phase extraction with in-situ polymerized stationary phase in a 
microfluidic device, J. Chromatogr. A. $1187 \quad$ (2008) 11-17. https://doi.org/10.1016/j.chroma.2008.01.084.

[5] G. Proczek, V. Augustin, S. Descroix, M.C. Hennion, Integrated microdevice for preconcentration and separation of a wide variety of compounds by electrochromatography, Electrophoresis. 30 (2009) 515-524. https://doi.org/10.1002/elps.200800308.

[6] C. Cakal, J.P. Ferrance, J.P. Landers, P. Caglar, Development of a micro-total analysis system ( $\mu$ TAS) for the determination of catecholamines, Anal. Bioanal. Chem. 398 (2010) 1909-1917. https://doi.org/10.1007/s00216-010-3998-8.

[7] Q.S. Kang, Y. Li, J.Q. Xu, L.J. Su, Y.T. Li, W.H. Huang, Polymer monolith-integrated multilayer poly(dimethylsiloxane) microchip for online microextraction and capillary electrophoresis, Electrophoresis. 31 (2010) 3028-3034. https://doi.org/10.1002/elps.201000210.

[8] N. Nordman, B. Barrios-Lopez, S. Laurén, P. Suvanto, T. Kotiaho, S. Franssila, R. Kostiainen, T. Sikanen, Shape-anchored porous polymer monoliths for integrated online solid-phase extractionmicrochip electrophoresis-electrospray ionization mass spectrometry: Microfluidics and Miniaturization, Electrophoresis. 36 (2015) 428-432. https://doi.org/10.1002/elps.201400278.

[9] S. Janků, M. Komendová, J. Urban, Development of an online solid-phase extraction with liquid chromatography method based on polymer monoliths for the determination of dopamine: Liquid Chromatography, J. Sep. Sci. 39 (2016) 4107-4115. https://doi.org/10.1002/jssc.201600818.

[10] P. Luliński, Molecularly imprinted polymers based drug delivery devices: a way to application in modern pharmacotherapy. A review, Mater. Sci. Eng. C. 76 (2017) 1344-1353. https://doi.org/10.1016/j.msec.2017.02.138.

[11] S. Piletsky, F. Canfarotta, A. Poma, A.M. Bossi, S. Piletsky, Molecularly imprinted polymers for cell $\begin{array}{lllll}\text { recognition, } & \text { Trends } & \text { Biotechnol. } & 38 & \text { (2019) 368-387. }\end{array}$ https://doi.org/10.1016/j.tibtech.2019.10.002.

[12] C.A. Tuwahatu, C.C. Yeung, Y.W. Lam, V.A.L. Roy, The molecularly imprinted polymer essentials: Curation of anticancer, ophthalmic, and projected gene therapy drug delivery systems, J. Controlled Release. 287 (2018) 24-34. https://doi.org/10.1016/j.jconrel.2018.08.023.

[13] Y. Cao, T. Feng, J. Xu, C. Xue, Recent advances of molecularly imprinted polymer-based sensors in the detection of food safety hazard factors, Biosens. Bioelectron. 141 (2019) 111447. https://doi.org/10.1016/j.bios.2019.111447.

[14] Y. Saylan, S. Akgönüllü, H. Yavuz, S. Ünal, A. Denizli, Molecularly imprinted polymer based sensors for medical applications, Sensors. 19 (2019) 1279. https://doi.org/10.3390/s19061279.

[15] O.S. Ahmad, T.S. Bedwell, C. Esen, A. Garcia-Cruz, S.A. Piletsky, Molecularly imprinted polymers in electrochemical and optical sensors, Trends Biotechnol. 37 (2019) 294-309. https://doi.org/10.1016/j.tibtech.2018.08.009.

[16] J.J. BelBruno, Molecularly imprinted polymers, Chem. Rev. 119 (2019) 94-119. https://doi.org/10.1021/acs.chemrev.8b00171.

[17] Y. Yin, Z. Dong, Q. Luo, J. Liu, Biomimetic catalysts designed on macromolecular scaffolds, Prog. Polym. Sci. 37 (2012) 1476-1509. https://doi.org/10.1016/j.progpolymsci.2012.04.001.

[18] M. Rutkowska, J. Płotka-Wasylka, C. Morrison, P.P. Wieczorek, J. Namieśnik, M. Marć, Application of molecularly imprinted polymers in analytical chiral separations and analysis, TrAC Trends Anal. Chem. 102 (2018) 91-102. https://doi.org/10.1016/j.trac.2018.01.011.

[19] V. Pichon, N. Delaunay, A. Combes, Sample preparation using molecularly imprinted polymers, Anal. Chem. 92 (2020) 16-33. https://doi.org/10.1021/acs.analchem.9b04816.

[20] T. Bouvarel, N. Delaunay, V. Pichon, Molecularly imprinted polymers in miniaturized extraction and separation devices, J. Sep. Sci. 44 (2021) 1727-1751. https://doi.org/10.1002/jssc.202001223.

[21] X. Zhang, S. Xu, Y.I. Lee, S.A. Soper, LED-induced in-column molecular imprinting for solid phase extraction/capillary electrophoresis, The Analyst. $138 \quad$ (2013) 2821. https://doi.org/10.1039/c3an00257h. 
[22] X. Zhang, D. Zhu, C. Huang, Y. Sun, Y.I. Lee, Sensitive detection of bisphenol A in complex samples by in-column molecularly imprinted solid-phase extraction coupled with capillary electrophoresis, Microchem. J. 121 (2015) 1-5. https://doi.org/10.1016/j.microc.2015.01.012.

[23] D. He, Z. Zhang, H. Zhou, Y. Huang, Micro flow sensor on a chip for the determination of terbutaline in human serum based on chemiluminescence and a molecularly imprinted polymer, Talanta. 69 (2006) 1215-1220. https://doi.org/10.1016/j.talanta.2005.12.043.

[24] J.D. Lei, A.J. Tong, Preparation of Z-L-Phe-OH-NBD imprinted microchannel and its molecular recognition study, Spectrochim. Acta. A. Mol. Biomol. Spectrosc. 61 (2005) 1029-1033. https://doi.org/10.1016/j.saa.2004.06.001.

[25] M. Szumski, D. Grzywiński, W. Prus, B. Buszewski, Monolithic molecularly imprinted polymeric capillary columns for isolation of aflatoxins, J. Chromatogr. A. 1364 (2014) 163-170. https://doi.org/10.1016/j.chroma.2014.08.078.

[26] L. Wen, X. Tan, Q. Sun, F. Svec, Y. Lv, "Smart" molecularly imprinted monoliths for the selective capture and easy release of proteins: Other Techniques, J. Sep. Sci. 39 (2016) 3267-3273. https://doi.org/10.1002/jssc.201600576.

[27] Z. Lin, J. Wang, X. Tan, L. Sun, R. Yu, H. Yang, G. Chen, Preparation of boronate-functionalized molecularly imprinted monolithic column with polydopamine coating for glycoprotein recognition and enrichment, J. Chromatogr. A. 1319 (2013) 141-147. https://doi.org/10.1016/j.chroma.2013.10.059.

[28] L. Schweitz, L.I. Andersson, S. Nilsson, Capillary electrochromatography with molecular imprintbased selectivity for enantiomer separation of local anaesthetics, J. Chromatogr. A. 792 (1997) 401-409. https://doi.org/10.1016/S0021-9673(97)00895-9.

[29] L. Schweitz, L.I. Andersson, S. Nilsson, Rapid electrochromatographic enantiomer separations on short molecularly imprinted polymer monoliths, Anal. Chim. Acta. 435 (2001) 43-47. https://doi.org/10.1016/S0003-2670(00)01210-1.

[30] X. Song, T. Zhou, J. Zhang, Y. Su, H. Zhou, L. He, Preparation and application of molecularly imprinted monolithic extraction column for the selective microextraction of multiple macrolide antibiotics from animal muscles, Polymers. $11 \quad$ (2019) 1109. https://doi.org/10.3390/polym11071109.

[31] M. Arabi, M. Ghaedi, A. Ostovan, Synthesis and application of in-situ molecularly imprinted silica monolithic in pipette-tip solid-phase microextraction for the separation and determination of gallic acid in orange juice samples, J. Chromatogr. B. 1048 (2017) 102-110. https://doi.org/10.1016/j.jchromb.2017.02.016.

[32] J. Chen, L. Bai, M. Tian, X. Zhou, Y. Zhang, Hollow-fiber membrane tube embedded with a molecularly imprinted monolithic bar for the microextraction of triazine pesticides, Anal Methods. 6 (2014) 602-608. https://doi.org/10.1039/C3AY41455H.

[33] G. Liang, H. Zhai, L. Huang, X. Tan, Q. Zhou, X. Yu, H. Lin, Synthesis of carbon quantum dots-doped dummy molecularly imprinted polymer monolithic column for selective enrichment and analysis of aflatoxin B1 in peanut, J. Pharm. Biomed. Anal. 149 (2018) 258-264. https://doi.org/10.1016/j.jpba.2017.11.012.

[34] H. Zhai, G. Liang, X. Guo, Z. Chen, J. Yu, H. Lin, Q. Zhou, Novel coordination imprinted polymer monolithic column applied to the solid-phase extraction of flumequine from fish samples, J. Chromatogr. B. 1118-1119 (2019) 55-62. https://doi.org/10.1016/j.jchromb.2019.04.023.

[35] G. Liang, X. Guo, X. Tan, S. Mai, Z. Chen, H. Zhai, Molecularly imprinted monolithic column based on functionalized $\beta$-cyclodextrin and multi-walled carbon nanotubes for selective recognition of benzimidazole residues in citrus samples, Microchem. J. 146 (2019) 1285-1294. https://doi.org/10.1016/j.microc.2019.02.064.

[36] C. Marchioni, T.M. Vieira, A.E. Miller Crotti, J.A. Crippa, M.E. Costa Queiroz, In-tube solid-phase microextraction with a dummy molecularly imprinted monolithic capillary coupled to ultraperformance liquid chromatography-tandem mass spectrometry to determine cannabinoids in plasma samples, Anal. Chim. Acta. 1099 (2020) 145-154. https://doi.org/10.1016/j.aca.2019.11.017. 
[37] X. Bi, W. Tian, X. Wang, W. Cao, L. Gao, S. Fan, Y. Wang, M. Wang, L. Niu, Preparation of a POSShybridized molecularly imprinted monolith for the analysis of baicalin and its analogues in a microwave-assisted extract from Scutellaria baicalensis by means of on-line SPME-HPLC and offline LC-MS/MS, Anal. Methods. 11 (2019) 2351-2361. https://doi.org/10.1039/C9AY00568D.

[38] S. Zhang, X. Sun, W. Wang, L. Cai, Determination of urinary 8-hydroxy-2'-deoxyguanosine by a combination of on-line molecularly imprinted monolithic solid phase microextraction with high performance liquid chromatography-ultraviolet detection: Sample Preparation, J. Sep. Sci. 36 (2013) 752-757. https://doi.org/10.1002/jssc.201200735.

[39] Q. Zhang, X. Xiao, G. Li, Porous molecularly imprinted monolithic capillary column for on-line extraction coupled to high-performance liquid chromatography for trace analysis of antimicrobials in food samples, Talanta. 123 (2014) 63-70. https://doi.org/10.1016/j.talanta.2014.02.010.

[40] T. Bouvarel, N. Delaunay, V. Pichon, Selective extraction of cocaine from biological samples with a miniaturized monolithic molecularly imprinted polymer and on-line analysis in nano-liquid $\begin{array}{lllll}\text { chromatography, Anal. Chim. Acta. } & 1096 \quad \text { (2020) }\end{array}$ https://doi.org/10.1016/j.aca.2019.10.046.

[41] B.L. Puet, K. Claussen, C. Hild, R. Heltsley, D.M. Schwope, Presence of Parent Cocaine in the Absence of Benzoylecgonine in Urine, J. Anal. Toxicol. 42 (2018) 512-517. https://doi.org/10.1093/jat/bky057.

[42] Arrêté du 13 décembre 2016 fixant les modalités du dépistage des substances témoignant de l'usage de stupéfiants, et des analyses et examens prévus par le code de la route et abrogeant l'arrêté du 5 septembre 2001 modifié fixant les modalités du dépistage des substances témoignant de l'usage de stupéfiants, et des analyses et examens prévus par le code de la route, 2016. 


\section{Supplementary material}

Simplified miniaturized analytical set-up based on molecularly imprinted polymer directly coupled to UV detection for the determination of benzoylecgonine in urine

Thomas Bouvarel ${ }^{\mathrm{a}}$, Christophe Chendo ${ }^{\mathrm{a}}$, Nathalie Delaunay ${ }^{\mathrm{a}}$, Valérie Pichon ${ }^{\mathrm{a}, \mathrm{b} *}$

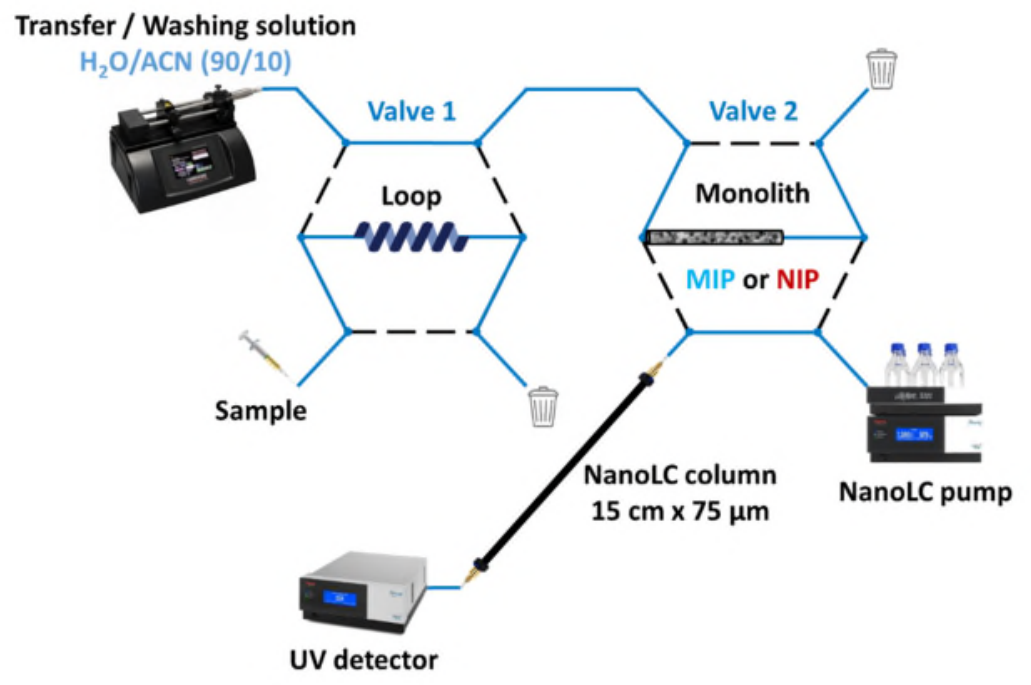

Figure S1. Set-up of the on-line coupling of the monolithic MIP/NIP (50 mm x $100 \mu \mathrm{m}$ i.d.) synthesized using thermal initiation with nanoLC-UV.

A
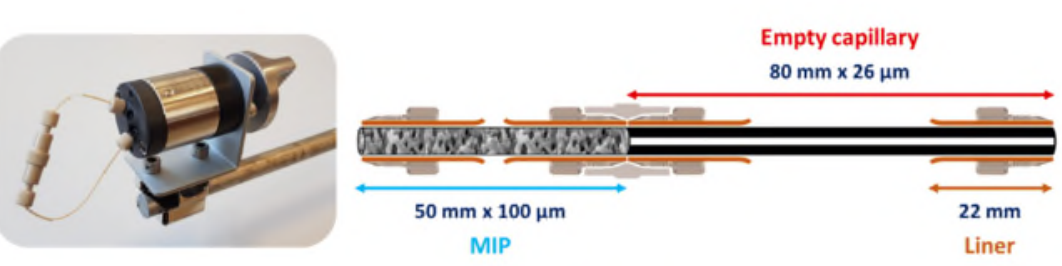

B
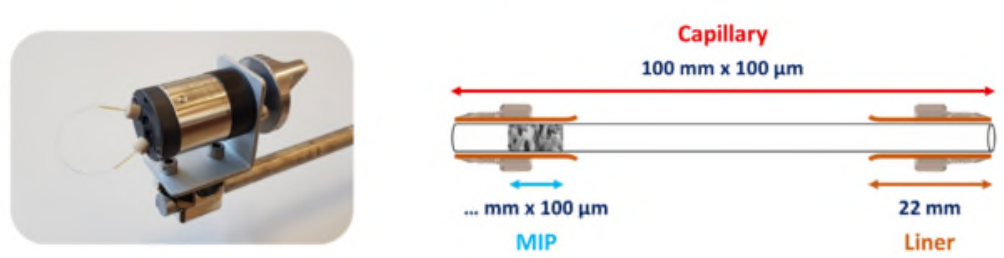

Figure S2. Experimental assembly allowing the connection on the valve of the monolithic MIP synthesized using (A) thermal or (B) UV irradiation. 

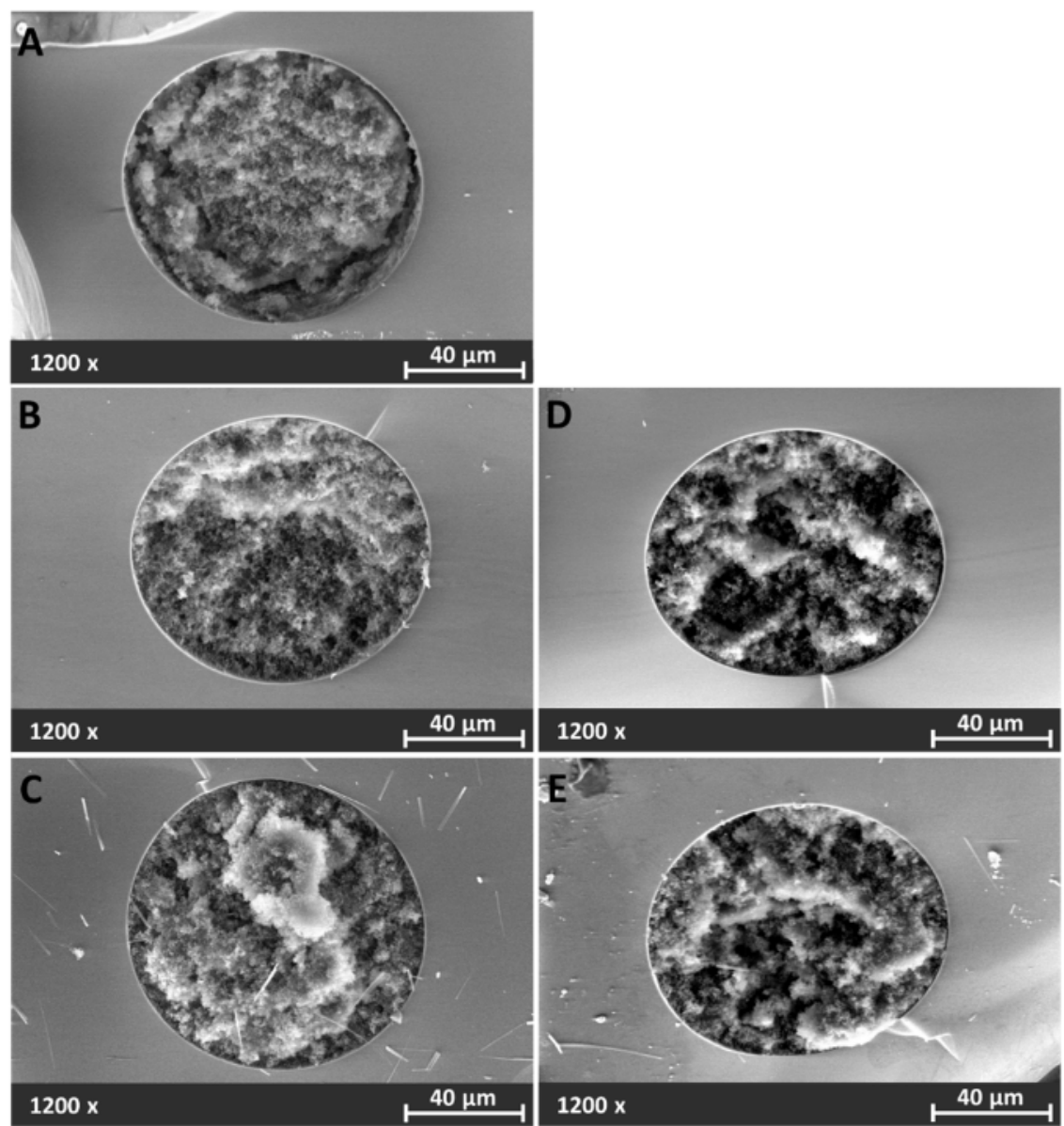

Figure S3. Scanning electron micrographs of the cross section of a $100 \mu \mathrm{m}$ i.d. capillary containing a monolithic $(A, B, C)$ NIP or $(D, E)$ MIP synthesized with UV initiation at room temperature during $(A) 15$ min and $(B, D)$ $30 \mathrm{~min}$ or $(\mathrm{C}, \mathrm{E})$ thermal initiation at $60^{\circ} \mathrm{C}$ during $24 \mathrm{~h}$. 

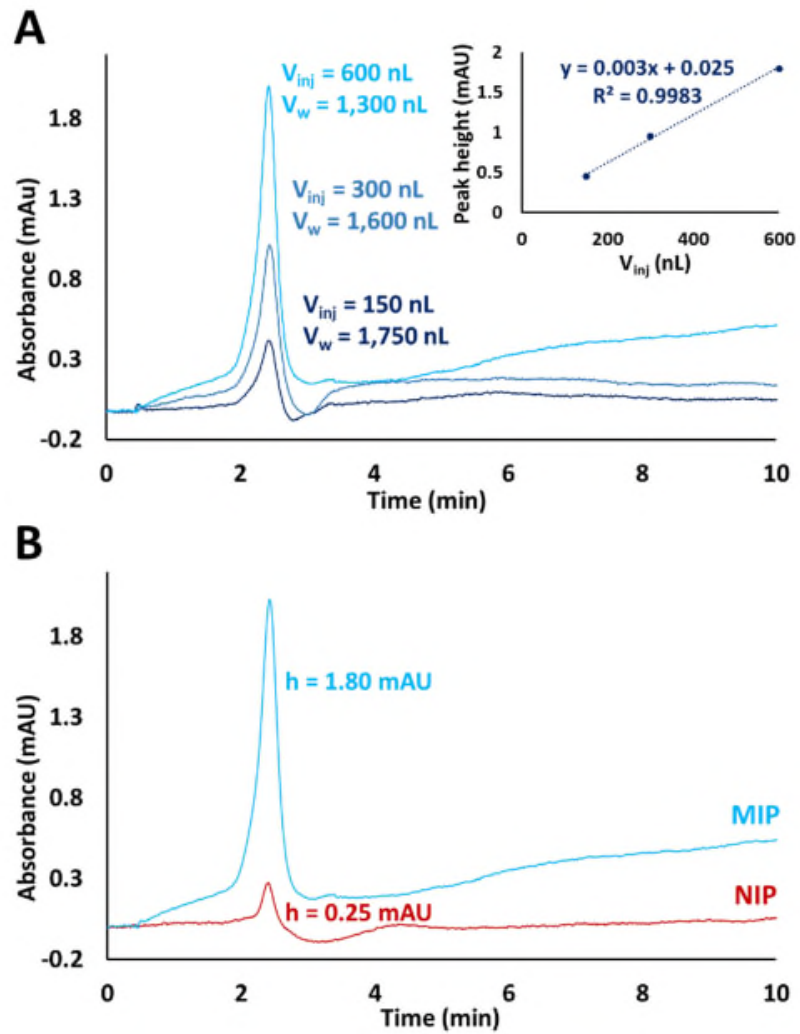

Figure S4. Chromatograms obtained for the analysis of different volumes $\left(V_{\text {inj }}\right)$ of BZE at $1 \mu g \mathrm{~mL}^{-1}$ in water on the MIP (10 mm x $100 \mu \mathrm{m}$ i.d.) synthesized in a $100 \mathrm{~mm} \times 100 \mu \mathrm{m}$ i.d. capillary under UV by adapting the volume of transfer/washing solution $\left(V_{w}\right)$ (insert: BZE peak height vs percolated sample volume) $(A)$ and comparison of chromatograms obtained using the MIP and the NIP ( $\left.V_{\text {inj }}=600 \mathrm{~nL}, \mathrm{~V}_{\mathrm{w}}=1,300 \mathrm{~nL}\right)(\mathrm{B})$. Transfer/washing solution: $\mathrm{H}_{2} \mathrm{O} / \mathrm{ACN}(90 / 10, \mathrm{v} / \mathrm{v})$, UV detection at $233 \mathrm{~nm}$. Configuration Figure 1 B2. Other conditions: see Section 2.5 .
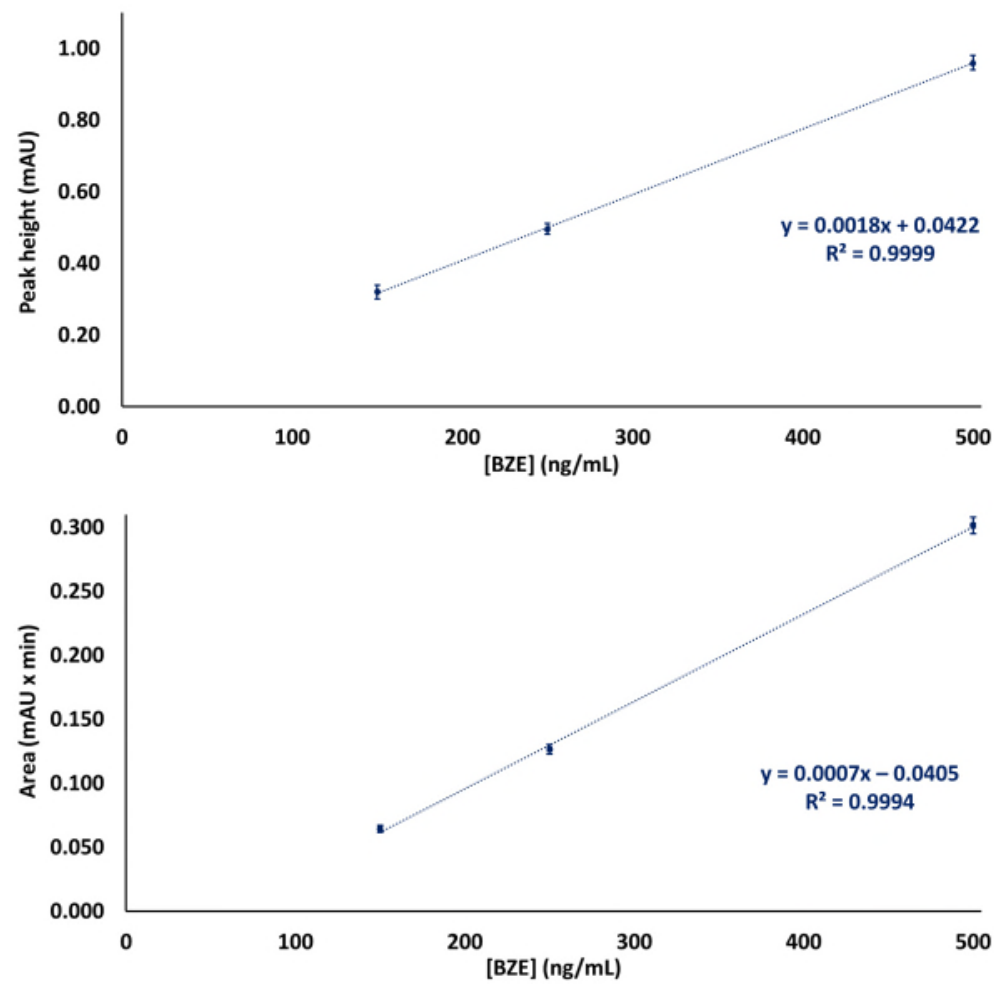

Figure S5. Curves plotting (Top) the peak height and (Down) peak area as a function of the BZE concentration from 150 to $500 \mathrm{ng} \mathrm{mL}^{-1}$ in $600 \mathrm{~nL}$ of spiked diluted urine (x2). 